Research Article

\title{
Performances and Working Mechanisms of Inclined Retaining Structures for Deep Excavations
}

\author{
Gang Zheng, ${ }^{1,2}$ Yuping Wang, ${ }^{1,2,3}$ Peng Zhang, ${ }^{3}$ Xuesong Cheng $\mathbb{D}^{1,2}$ Wenlong Cheng, \\ Yuebin Zhao, ${ }^{1,2}$ and Xinhao $\mathrm{Li}^{1,2}$ \\ ${ }^{1}$ MOE Key Laboratory of Coast Civil Structure Safety, Tianjin University, Tianjin 300072, China \\ ${ }^{2}$ Department of Civil Engineering, Tianjin University, Tianjin 300072, China \\ ${ }^{3}$ Qinghai Nationalities University, Xining 810007, China \\ ${ }^{4}$ Tianjin Chengjian University, Tianjin 300384, China
}

Correspondence should be addressed to Xuesong Cheng; cheng_xuesong@163.com

Received 2 September 2019; Accepted 13 February 2020; Published 8 June 2020

Academic Editor: Khalid Abdel-Rahman

Copyright ( 92020 Gang Zheng et al. This is an open access article distributed under the Creative Commons Attribution License, which permits unrestricted use, distribution, and reproduction in any medium, provided the original work is properly cited.

Because of the limits of struts, braceless retaining structures (BRS) have become a preferred option in deep excavation engineering. A type of BRS, that is, inclined retaining system, has been successfully applied in several projects. However, its performance and working mechanism have not been systematically studied. A case study and finite element results in this study show that inclined piles (IP) are more effective than vertical piles (VP), while composite inclined retaining structures (CIRSs) are more effective than IP in terms of deflection and bending moment reduction. The deformation-control mechanism of IP mainly comes from the decrease in the active earth pressure. For CIRSs, the working mechanism is governed by several combined effects, that is, the rigid frame effect, inclined strut effect, earth berm effect, and gravity wall effect. For instance, in composite vertical and inward-inclined piles (VIIP), inclined piles function as struts for the vertical piles in this rigid frame system and frictional force between the soil and the inclined piles significantly influences its retaining performance; the soil between the vertical and inclined piles plays a role similar to an earth berm; additionally, the entire retaining system is similar to a gravity retaining wall, which has relatively high overturning stability.

\section{Introduction}

In the urban area of China, an increasing number of high-rise buildings and underground utility tunnels are being constructed, and correspondingly, excavation projects are becoming progressively deeper, larger, and longer. However, deep excavation may induce excessive soil deformation and ground settlement, which may damage adjacent buildings, tunnels, and municipal pipes. To protect the surrounding environment during excavation, it is necessary to adopt effective measures to limit the deflection of the retaining system and the ground settlement. Diaphragm walls or piles with one or more levels of horizontal struts or ground anchors are commonly used to reduce excavation-induced ground movement $[1,2]$.

Berm-supported diaphragm walls or piles [3], doublerow piles [4], and multibench retaining systems [5] are common braceless retaining structures that eliminate horizontal struts and ground anchors. However, berms occupy large areas when the excavation depth is relatively large and cause delays in the construction of underground structures in the berm areas. The excavation depth of double-row piles is limited, generally less than $8 \mathrm{~m}$ in soft soil areas.

An excavation with a depth of $9.6 \mathrm{~m}$ retained by the inclined steel sheet piles with a berm was successfully conducted in sandy ground. Furthermore, the centrifuge model experiment based on this practical case demonstrated that the deformation of inclined piles was approximately $30 \%$ less than that of vertical piles [6]. However, composite structures with both inclined and vertical piles were not investigated in study of Maeda et al. [6]. Model experiments of a retaining wall using batter piles were performed in marine clay [7]. Test results showed that the lateral 
displacement of the retaining structure decreased by approximately $40 \%$ when inclined piles were present. Jeldes et al. [8] introduced a new type of earth-retaining structure named piling framed retaining wall (PFRW), which consists of vertical and battered piles, walers, and tie-down anchors and is applicable for soils underlain by rock. Simplified design equations were developed to predict the earth pressures acting on the battered wall and the overturning moments for stability analyses. Previous research has indicated that battered piles play an important role in decreasing the deformation and internal forces on retaining structures. However, the working mechanism of the retaining structures consisting of inclined piles used for excavations in soft soil areas has not yet been systematically investigated.

In addition to purely inclined piles structures (IP), three types of composite inclined retaining structures (CIRSs), that is, composite vertical and outward-inclined retaining piles (VOIP), composite vertical and inward-inclined retaining piles (VIIP), and composite outward- and inwardinclined retaining piles (OIIP), have been proposed to improve existing cantilever retaining structures. Schematic diagrams and profiles of the inclined pile retaining structures and different types of CIRSs are shown in Figures 1(a)-1(d), respectively. In each type of CIRS, the vertical piles are aligned with the inclined piles by a large cast-in-place concrete capping beam on top. VIIP structures using precast rectangular piles have been applied in several projects in Tianjin, China, and have been performed well. A case study is introduced in Section 2. Three-dimensional finite element analyses (FEA) were conducted to investigate the performance and mechanism of these new retaining structures. The retaining capacities of the CIRSs were compared with those of VP and VP + S (for brevity, the traditional cantilever structure consisting of vertical retaining piles is abbreviated $\mathrm{VP}$, and the vertical retaining pile structure with a level of struts is abbreviated $\mathrm{VP}+\mathrm{S}$ ). The deformations, internal forces, and soil-structure interaction for different types of CIRSs were analyzed to investigate the working mechanisms of CIRSs. Based on the case study and numerical simulations, the excellent retaining performances of CIRSs and their working mechanisms were addressed.

\section{Case Study}

2.1. Project Overview. The Haiheyuan project was located in Tianjin, China, and the plan layout of the excavation is shown in Figure 2(a). The excavation area was $46000 \mathrm{~m}^{2}$, and the main excavation depth was $4.9 \mathrm{~m}$, with a maximum excavation depth of $6.3 \mathrm{~m}$. In plain view, the shape of the project was approximately a rectangle. Two profiles of the ground are shown in Figures 2(b) and 2(c), and the soil parameters for different soil layers are listed in Table 1. The soil parameters were derived from a series of laboratory tests using soil samples taken by a thin wall sampler (e.g., the oven-drying method, water pycnometry, triaxial undrained tests (CU), and oedometer test). This ground site has a very thick mucky silty clay layer, which is very adverse for the control of the deformation of the excavation. Traditionally, for the excavation with the depth of 4.5-6 $\mathrm{m}$ at such ground condition, sheet piles with a level of struts are usually adopted. However, because the excavation area was very large, the struts would be very costly and could delay the construction processes.

In addition, to speed up the construction, the supporting piles adopted in the field were precast rectangular piles with a cross section of $375 \mathrm{~mm} \times 500 \mathrm{~mm}$ and a circular hole of $\phi=210 \mathrm{~mm}$, as shown in Figures 2(b) and 2(c). This type of pile was prefabricated with grade 80 concrete and cured with steam and used centrifugal and prestressing techniques. The flexural stiffness and strength of these prefabricated piles are much higher than those of the cast-in-place piles with the same cross-sectional area.

2.2. Optimization of the Retaining Structure. In order to optimize the design scheme, several types of retaining structures including VP, IP with different inclined angles, VOIP with inclination angle of $20^{\circ}\left(\mathrm{VOIP}-20^{\circ}\right)$, VIIP- $20^{\circ}$, and $\mathrm{VP}+\mathrm{S}$ were simulated by FEA using the soil condition of profile $\mathrm{M}-1$. The section and plan views of the retaining structures of IP and VIIP-20 are shown in Figures 2(b) and 2(c). A typical FEA model of VIIP-20 was shown in Figure 3, and the FEA models of other retaining structures are similar to that of VIIP- $20^{\circ}$. Parameters of retaining pile, capping beam, and strut are shown in Table 2, respectively. The excavation depth is $4.9 \mathrm{~m}$, and the groundwater level is $-2 \mathrm{~m}$. Other details of the FEA models are introduced in Section 3.1.

The finite element results of the maximum horizontal displacements for different retaining structures are summarized in Figure 4. VP has the largest displacement among these retaining structures. For IP, as the inclined angle increases, the pile displacement decreases. The retaining performance of VOIP- $20^{\circ}$ is slightly better than that of IP$20^{\circ}$, while the retaining performance of VIIP- $20^{\circ}$ is much better than that of VOIP- $20^{\circ}$. The displacement of VP $+\mathrm{S}$ is the smallest, but the displacement of VIIP- $20^{\circ}$ is very close to that of $\mathrm{VP}+\mathrm{S}$.

Considering the results in Figure 4 and the shortcomings of struts, VIIP- $20^{\circ}$ was selected as the main retaining system of the excavation. In addition, to compare the retaining performances of VP and VIIP-20, VP was used at profile M-2 as a reference case. The precast piles, including inclined and vertical piles, were both driven by a professionally custom-made static pressure pile driver, as shown in Figure 5(a). A reinforced concrete capping beam composed of grade 35 concrete was set at the top of the vertical and inclined piles and the construction process was shown in Figure 5(b).

2.3. Field Monitoring Results and Discussions. Three inclinometers, that is, $\mathrm{M}-1, \mathrm{M}-2$, and $\mathrm{M}-3$, were set at profiles retained by VIIP, VP, and $\mathrm{VII}_{2} \mathrm{P}$ (composite retaining structure with retaining element of two inclined piles and one vertical pile, as shown in Figure 5(c)), respectively, as shown in Figure 2(a). The inclinometers were inserted into the circular holes of the rectangular piles. Then, cement 

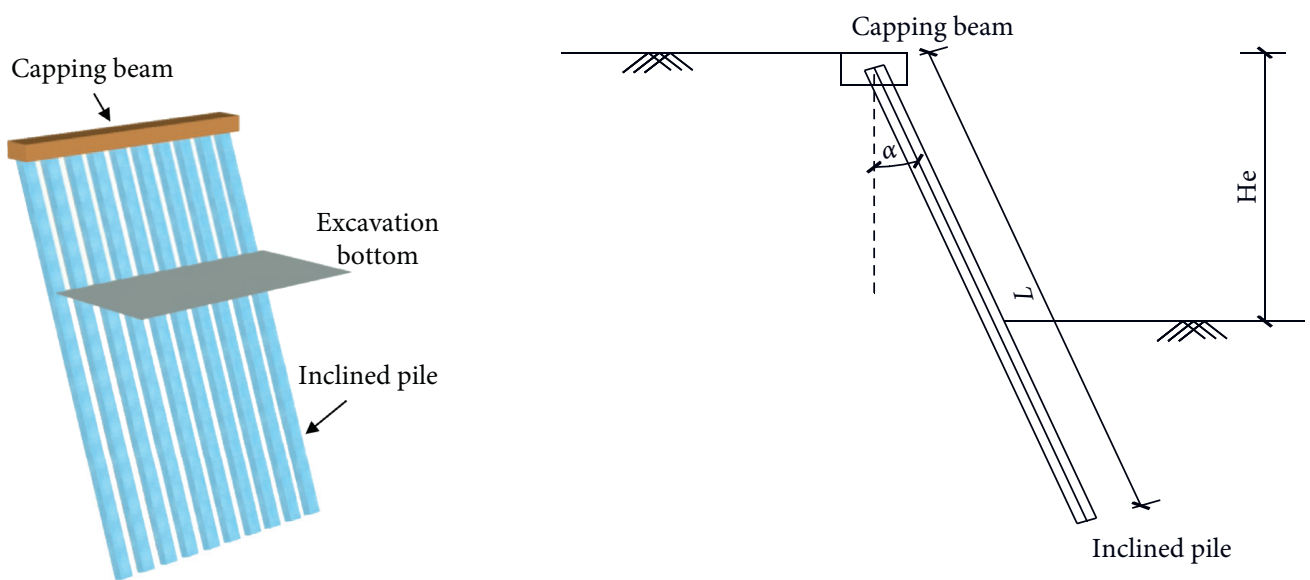

(a)
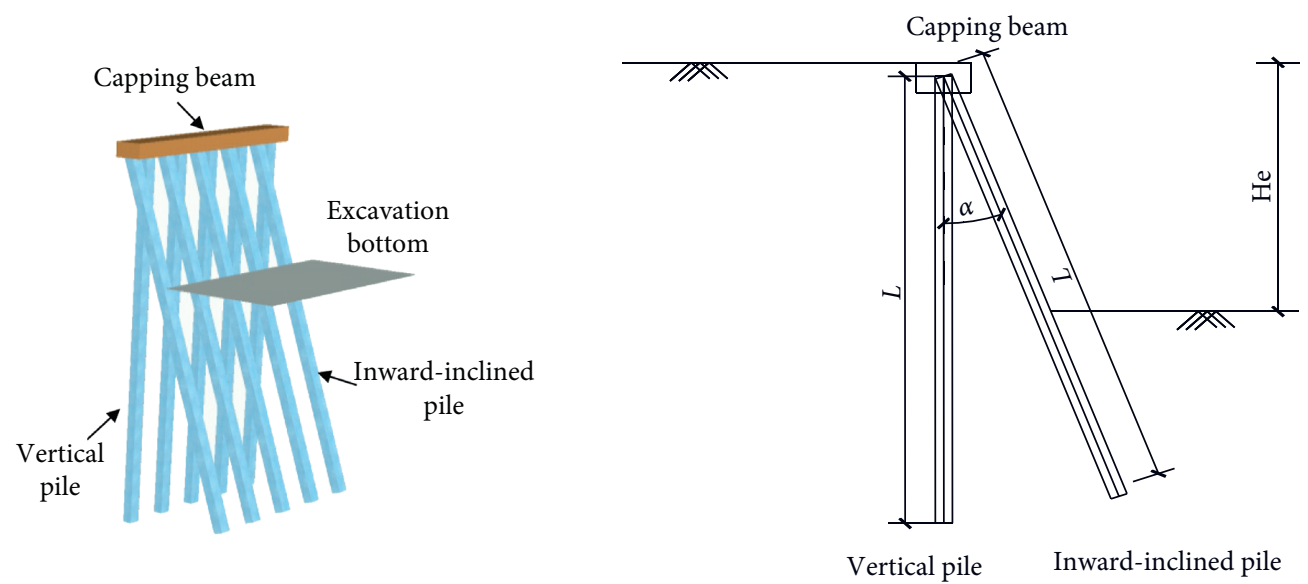

(b)
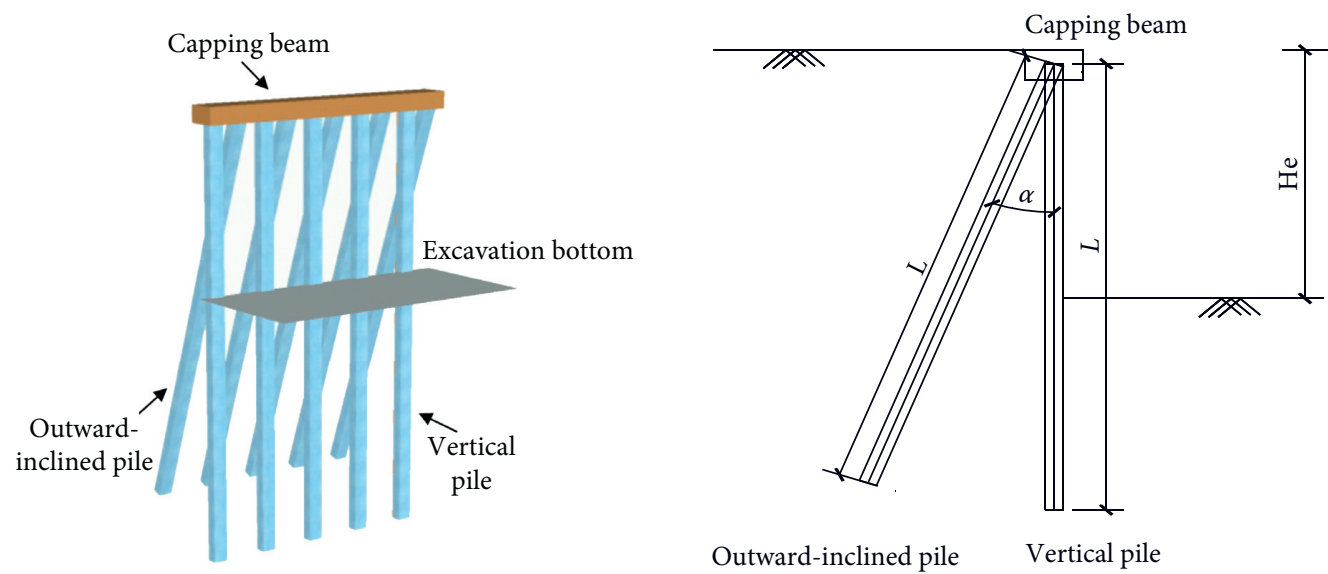

(c)

Figure 1: Continued. 


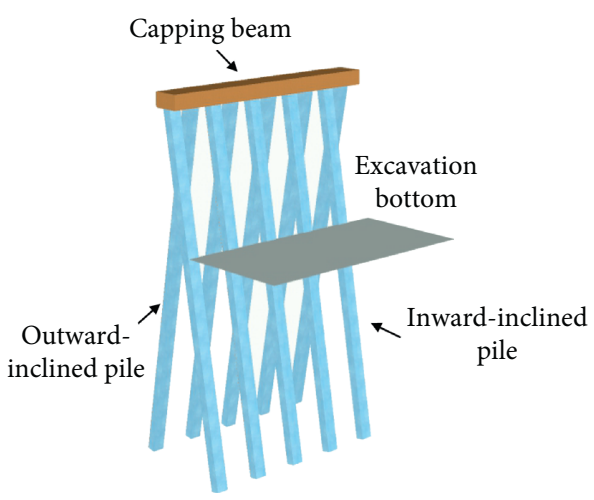

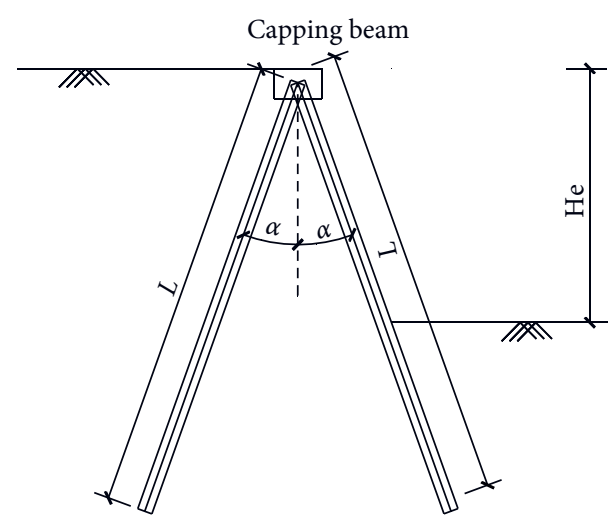

Outward-inclined pile
Inward-inclined pile

(d)

FIGURE 1: 3D diagram and profile of different types of inclined retaining structures. (a) Inclined piles (IP). (b) Vertical and outward-inclined piles (VOIP). (c) Vertical and inward-inclined piles (VIIP). (d) Outward- and inward-inclined piles (OIIP).

grout was poured into the holes to fix the inclinometers. Unfortunately, M-3 did not record data because the measuring instrument was broken during construction. The monitoring results of M-1 and M-2 were shown in Figure 6. The maximum displacement of the conventional VP reached $103 \mathrm{~mm}$, while the maximum displacement of the VIIP was only $38 \mathrm{~mm}$. In addition, the measured results were consistent with the finite element results, which proves the validity of the finite element model. Although the pile length and pile spacing were exactly the same for VP and VIIP in this project, the displacement of VIIP- $20^{\circ}$ was approximately $60 \%$ less than that of VP, which verified that the retaining performance of VIIP is much better than that of VP. In the next several sections, the performances and working mechanisms of CIRSs, including VIIP, will be systematically further investigated.

\section{Three-Dimensional Finite Element Model}

3.1. Model Geometry, Mesh, and Boundary Conditions. Several series of 3D simulations were conducted using PLAXIS 3D [9], to investigate the performance and mechanism of the new retaining structures. For each series, the retaining structures used for comparison included VP, $\mathrm{VP}+\mathrm{S}, \mathrm{IP}, \mathrm{VOIP}, \mathrm{VIIP}$, and OIIP. The lengths of retaining pile $L$ were $15 \mathrm{~m}, 20 \mathrm{~m}$, and $25 \mathrm{~m}$, and the corresponding normal excavation depths He were $6 \mathrm{~m}, 8 \mathrm{~m}$, and $10 \mathrm{~m}$, respectively. The inclination angle of piles $\alpha$ varied from 0 to 30 degree. Figure 3 shows the 3D finite element mesh for a typical excavation. The excavation width was assumed to be $80 \mathrm{~m}$. Because of the symmetry, a half model of the entire excavation site with a width of $40 \mathrm{~m}$ was established. To eliminate the boundary effects, the model height and width beyond the excavation extended to 6.5 times and 5 times the maximum excavation depth, respectively [10]. Although the excavation length was supposed to be infinite, considering symmetry, the $Y$ direction was $1.4 \mathrm{~m}$ and contained one intact pile in the middle and two half piles on each side to save calculation costs, as shown in Figure 3. Soil movements normal to the four vertical sides were restrained (roller boundary), and soil movements were restrained in all directions at the bottom of the geometry (fixed boundary). The FE mesh consisted of approximately 12000 elements in each case.

3.2. Soil Constitutive Model, Model Parameters, and Modeling Procedure. To better conduct the comparative analysis and parameter study, a single layer of the soil in the case study of Section 2, that is, 4-1 clay layer in Table 1, was adopted in the model to study the performances and mechanisms of various types of inclined retaining structures. The behavior of the soil was assumed to follow the Hardening Soil model (HS model) [11].

Ten-node tetrahedral elements were employed to simulate the soil mass. The retaining piles and capping beam were the same as those used in the above-mentioned case in the last section, and their properties were listed in Table 2. The pile spacing was uniformly $700 \mathrm{~mm}$ in all cases. Six-node plate elements were used to model the retaining piles. The width of a single pile model was equal to the central distance between two adjacent retaining piles. The thickness of the plate was calculated based on the equivalent values of the flexible stiffness, EI [10]. Three-node beam elements were used to model the capping beam. For comparison with the CIRSs, a model of VP $+\mathrm{S}$ was also established. The struts adopted were steel pipes with diameters of $609 \mathrm{~mm}$ and simulated using anchor elements, as listed in Table 2. In addition, 12-node interface elements were applied to model the pile-soil interaction behavior, and the strength of the interface was set to $70 \%$ of that of the surrounding soil.

The soil was excavated at intervals of $2 \mathrm{~m}$ in each step. The groundwater level was $2 \mathrm{~m}$ below the ground surface, and the pore water pressure was assumed to be in the hydrostatic condition. The groundwater level inside the excavation was lowered to the excavation bottom in each excavation step, while that outside the excavation remained at the original level. This hypothetical excavation procedure was adopted for the following simulations. 


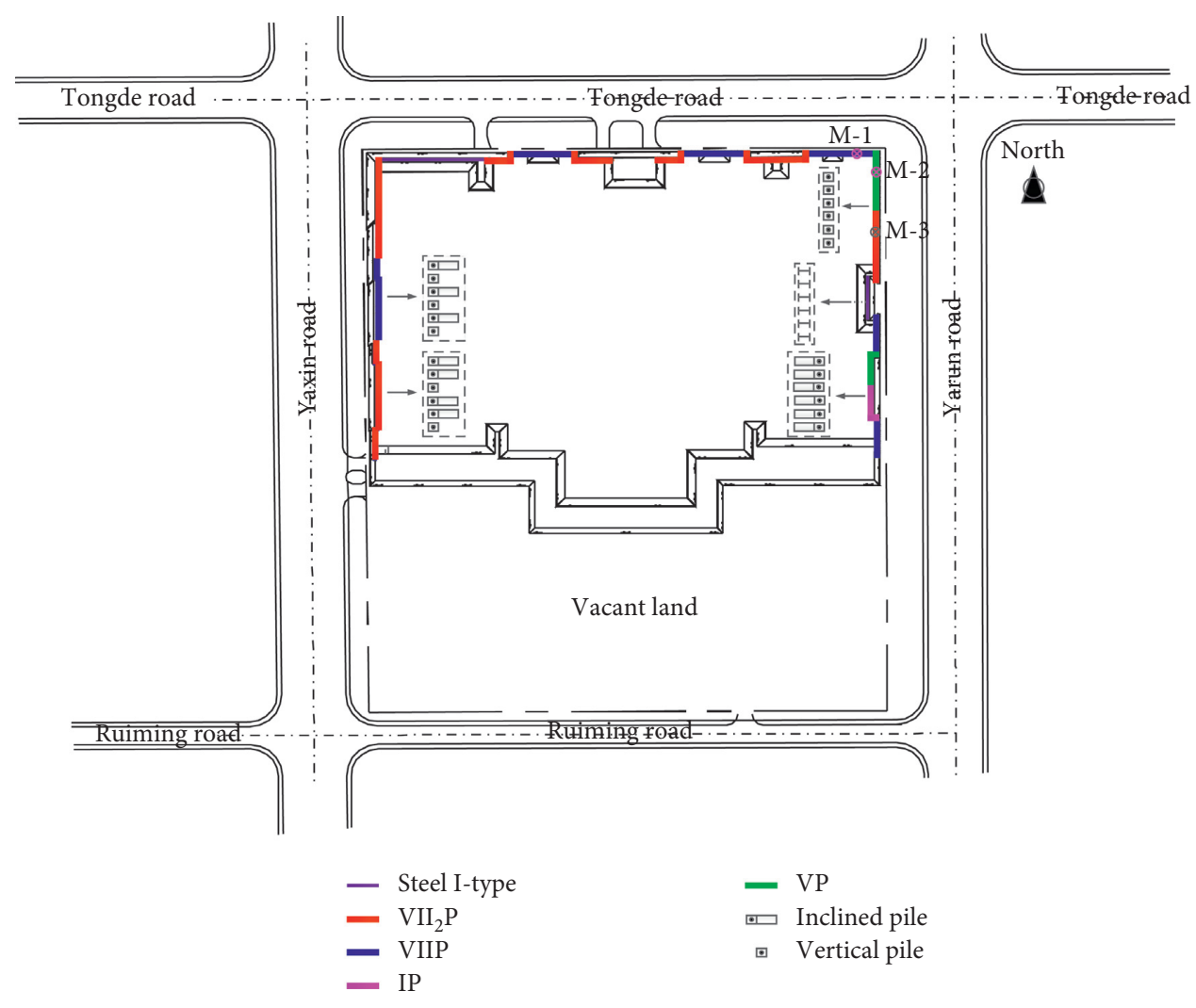

(a)
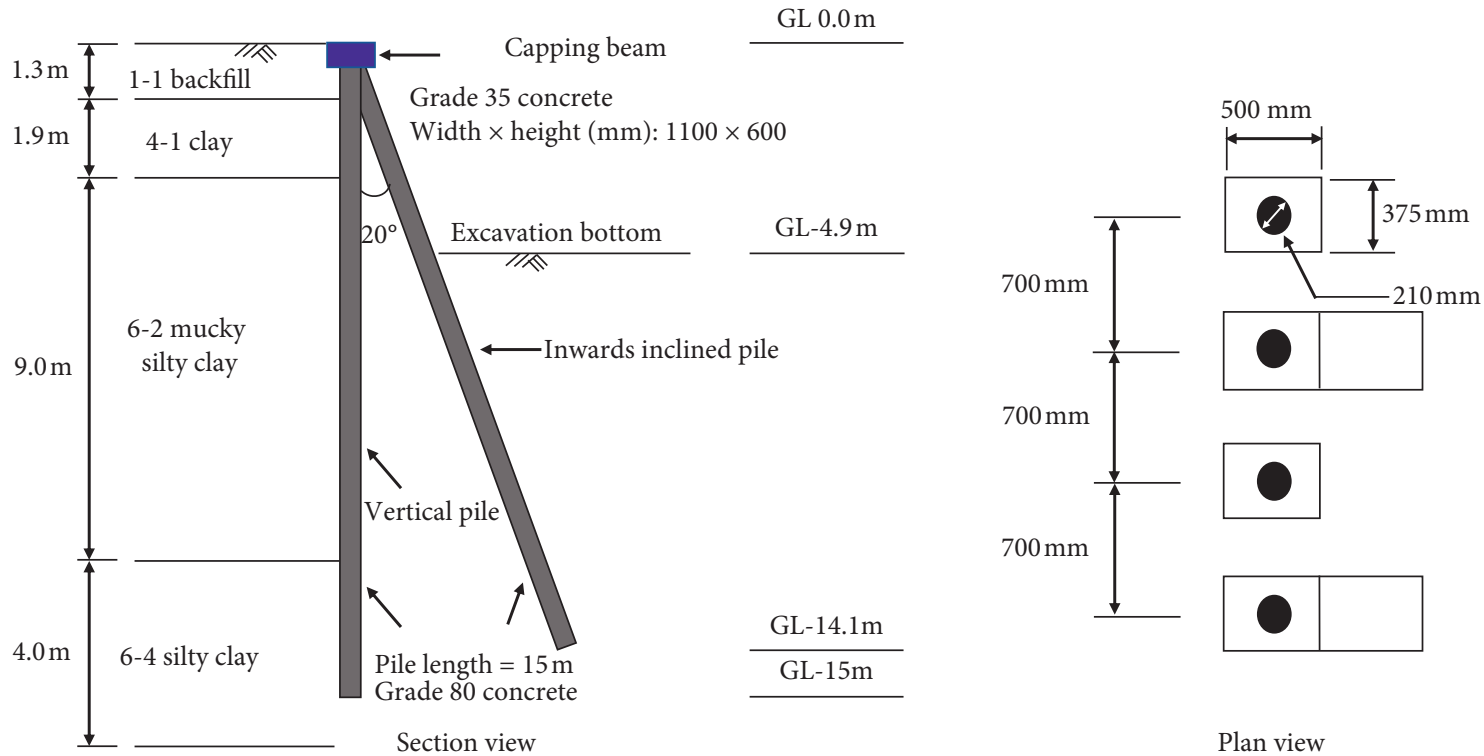

(b)

Figure 2: Continued. 


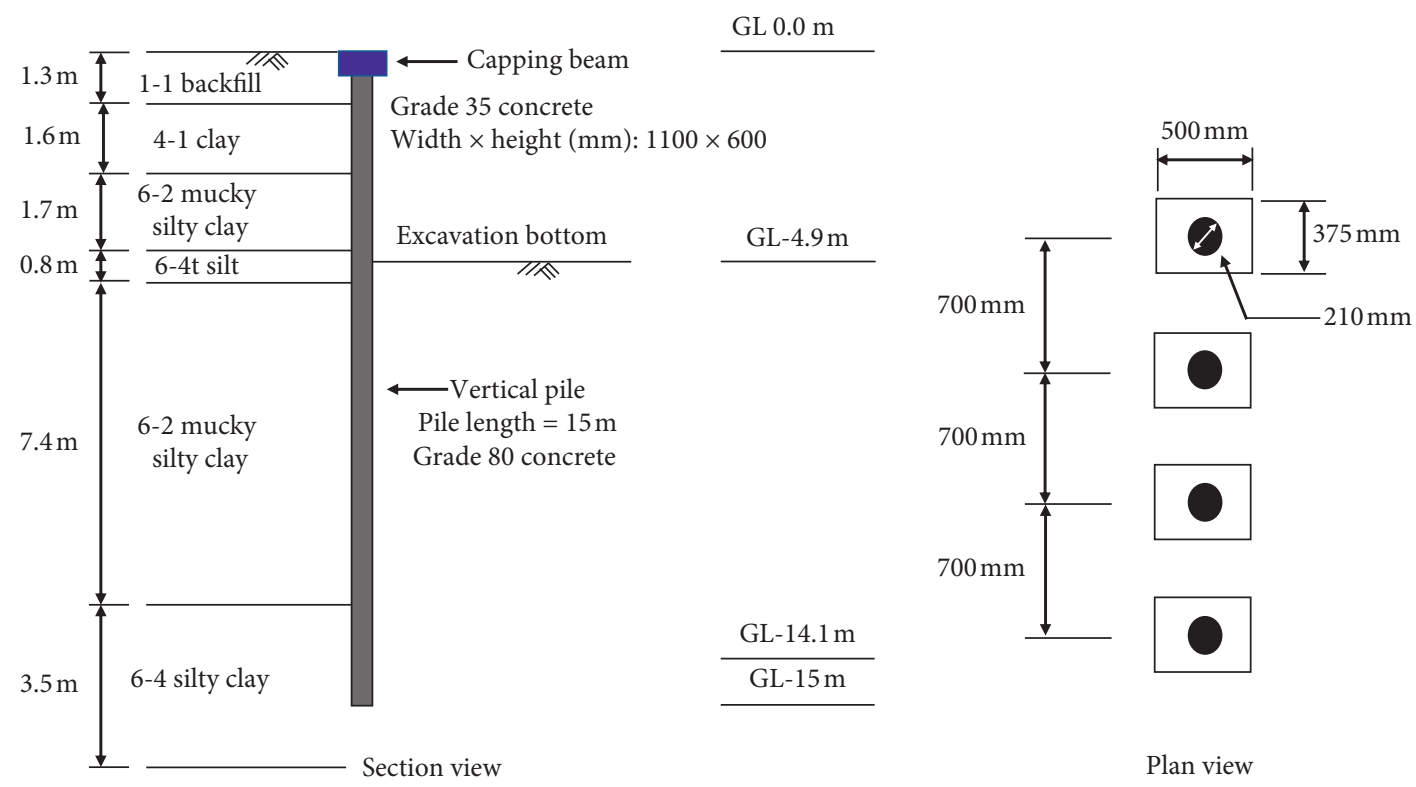

(c)

FIgure 2: (a) Plan layout of the Haiheyuan project. (b) Profile and plan views of excavations retained by VIIP named M-1. (c) Profile and plan views of excavations retained by VP named M-2.

TABLE 1: Soil parameters of Haiheyuan project.

\begin{tabular}{lccccccccc}
\hline Layer number & Soil type & Thickness $(\mathrm{m})$ & $\gamma\left(\mathrm{kN} / \mathrm{m}^{3}\right)$ & $c^{\prime}(\mathrm{kPa})$ & $\varphi^{\prime}\left({ }^{\circ}\right)$ & $E_{50}^{\mathrm{ref}}(\mathrm{MPa})$ & $E_{\mathrm{oed}}^{\mathrm{ref}}(\mathrm{MPa})$ & $E_{\text {ur }}^{\mathrm{ref}}(\mathrm{MPa})$ & $e$ \\
\hline $1-1$ & Backfill & 1.3 & 18.50 & 12.4 & 16.10 & 4.38 & 4.38 & 26.28 & 0.94 \\
$4-1$ & Clay & 1.9 & 18 & 1 & 28 & 5.05 & 5.05 & 15.15 & 0.88 \\
$6-2$ & Mucky silty clay & 9 & 18.55 & 1 & 26 & 5.22 & 4.21 & 40.58 & 0.88 \\
$6-4$ & Silty clay & 4 & 19 & 1 & 32 & 17.723 & 12.406 & 88.6 & 0.79 \\
\hline
\end{tabular}

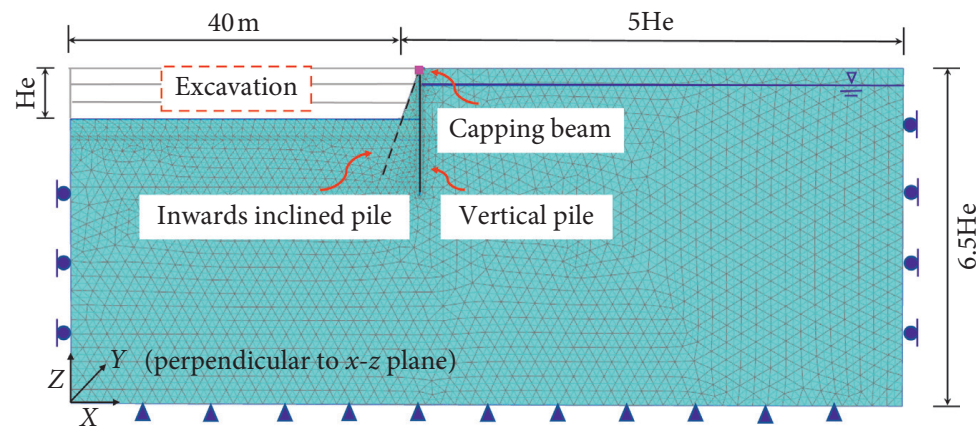

(a)

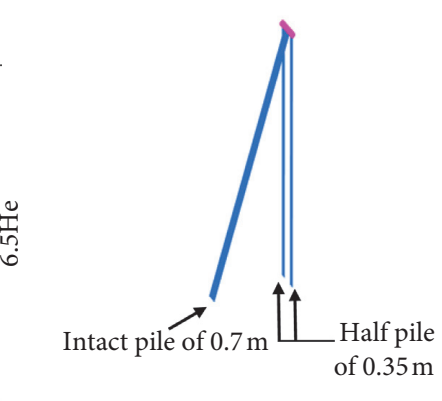

(b)

FIgURE 3: An excavation retained by VIIP. (a) Finite element mesh; (b) 3D view of VIIP.

TABLE 2: Parameters of structures in finite element models.

\begin{tabular}{|c|c|c|c|c|}
\hline Material, element & & & eters & \\
\hline Retaining pile, plate & $\begin{array}{l}\text { Width (mm) } \\
375\end{array}$ & $\begin{array}{l}\text { Height }(\mathrm{mm}) \\
500\end{array}$ & $\begin{array}{l}\text { Young's modulus (GPa) } \\
38 \\
\end{array}$ & $\begin{array}{c}\text { Poisson's ratio } \\
0.2 \\
\end{array}$ \\
\hline Capping beam, beam & $\begin{array}{l}\text { Width (mm) } \\
1100\end{array}$ & $\begin{array}{l}\text { Height }(\mathrm{mm}) \\
600\end{array}$ & $\begin{array}{l}\text { Young's modulus (GPa) } \\
31.5\end{array}$ & $\begin{array}{c}\text { Poisson's ratio } \\
0.2\end{array}$ \\
\hline Strut, anchor & $\begin{array}{c}\text { Diameter }(\mathrm{mm}) \\
609\end{array}$ & $\begin{array}{c}\text { Thickness }(\mathrm{mm}) \\
16\end{array}$ & $\begin{array}{l}\text { Young's modulus (GPa) } \\
210\end{array}$ & $\begin{array}{c}\text { Poisson's ratio } \\
0.2\end{array}$ \\
\hline
\end{tabular}




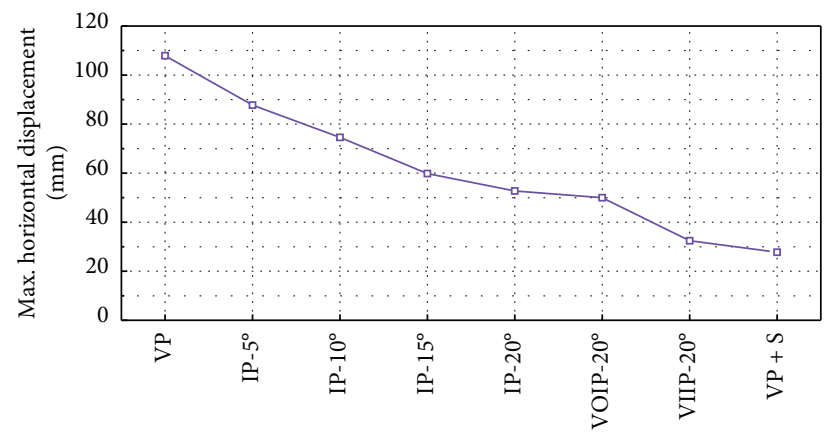

Figure 4: Maximum horizontal displacement of different retaining structures in profile M-1 calculated by FEM.

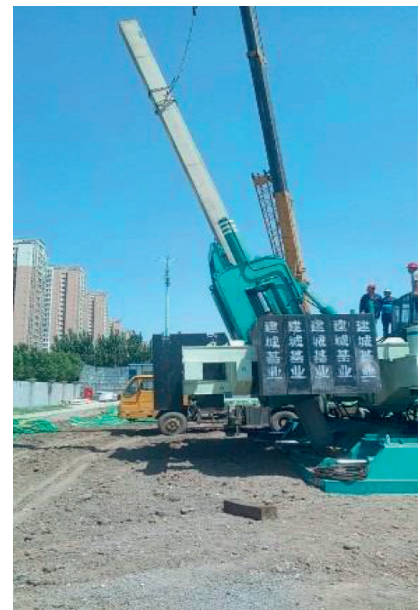

(a)

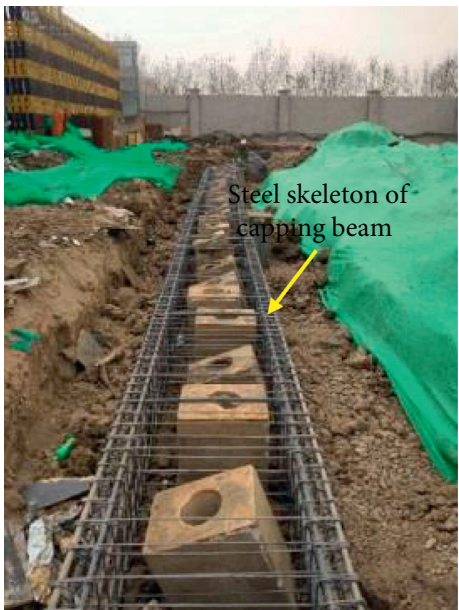

(b)

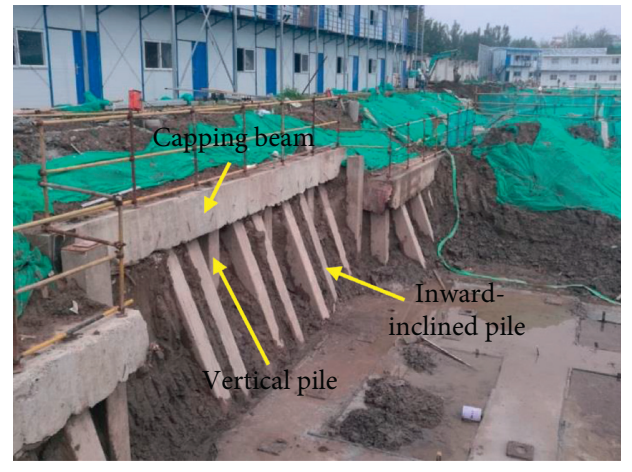

(c)

FIgURE 5: The site construction of inclined retaining structures. (a) Static pressure pile driver. (b) Construction of capping beam. (c) Excavation retained by $\mathrm{VII}_{2} \mathrm{P}-20^{\circ}$.

\section{Comparison of Performances of Various Types of Inclined Retaining Structures}

In this section, inclination angles of $10^{\circ}$ and $20^{\circ}$ were considered for the inclined piles in the different types of retaining systems. The maximum horizontal displacements and the maximum bending moments of the retaining piles for excavation depths of $6 \mathrm{~m}$ (pile length: $15 \mathrm{~m}$ ), $8 \mathrm{~m}$ (pile length: $20 \mathrm{~m}$ ), and $10 \mathrm{~m}$ (pile length: $25 \mathrm{~m}$ ) are shown in Figures 7 and 8, respectively.

As shown in Figure 7, although the embedding ratios of the retaining structures for the three excavation depths were the same (1.5), when the excavation depth was larger, both the horizontal displacement and the bending moment in the retaining piles increased. For the same excavation depth, IP had better performance than VP in reducing pile deflection. For each retaining system with inclined piles, when the inclination angle increased from $10^{\circ}$ to $20^{\circ}$, the maximum horizontal displacement decreased significantly. When the inclined piles in different types of retaining systems have the same inclination angle, VOIP were better than IP, while OIIP and VIIP yielded the greatest performance. For relatively deeper excavations and smaller inclination angles, the performance of OIIP was slightly better than that of VIIP in reducing wall deflection.

To quantitatively evaluate the effectiveness of different types of retaining structures in reducing the excavation deformation compared with VP, the reduction ratio in the maximum horizontal displacement of the retaining structure (MR) is defined as

$$
\mathrm{MR}=\frac{\delta_{h m, v}-\delta_{h m, b}}{\delta_{h m, v}} \times 100 \%,
$$

where $\delta_{h m, v}$ and $\delta_{h m, b}$ are the maximum horizontal displacements of VP and compared retaining systems (such as IP, CIRSs, and VP $+\mathrm{S}$ ), respectively.

As shown in Figure 7, for an excavation depth of $6 \mathrm{~m}$ and an inclination angle of $20^{\circ}$, the MR values were $57.32 \%$, $59.78 \%, 76.86 \%, 78.52 \%$, and $79.16 \%$ for IP, VOIP, VIIP, OIIP, and VP $+\mathrm{S}$, respectively. CIRSs, such as VIIP and OIIP, even showed similar performance as $\mathrm{VP}+\mathrm{S}$ in controlling the deformation of the excavation. Therefore, for the excavations in this section, if the traditional cantilever piles (i.e., VP) cannot satisfy the deformation-control requirement, it is possible to replace the traditional strutted retaining scheme $(\mathrm{VP}+\mathrm{S})$ with a type of CIRS, such as VIIP or OIIP, which have a similar capacity to control 


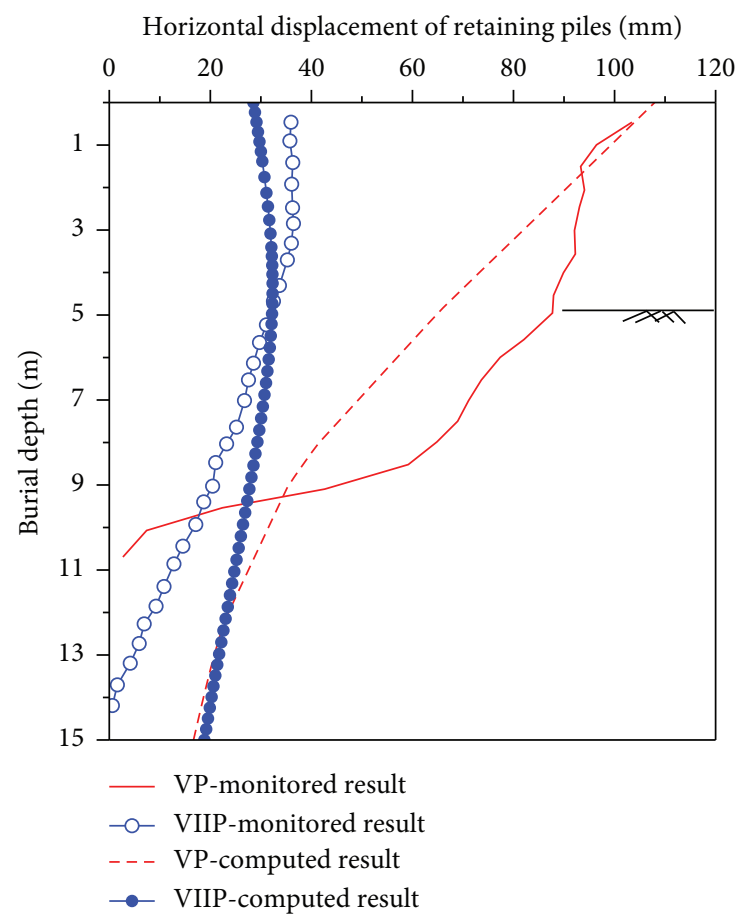

FIgure 6: Monitored and computed results of VP and VIIP- $20^{\circ}$ in the field.

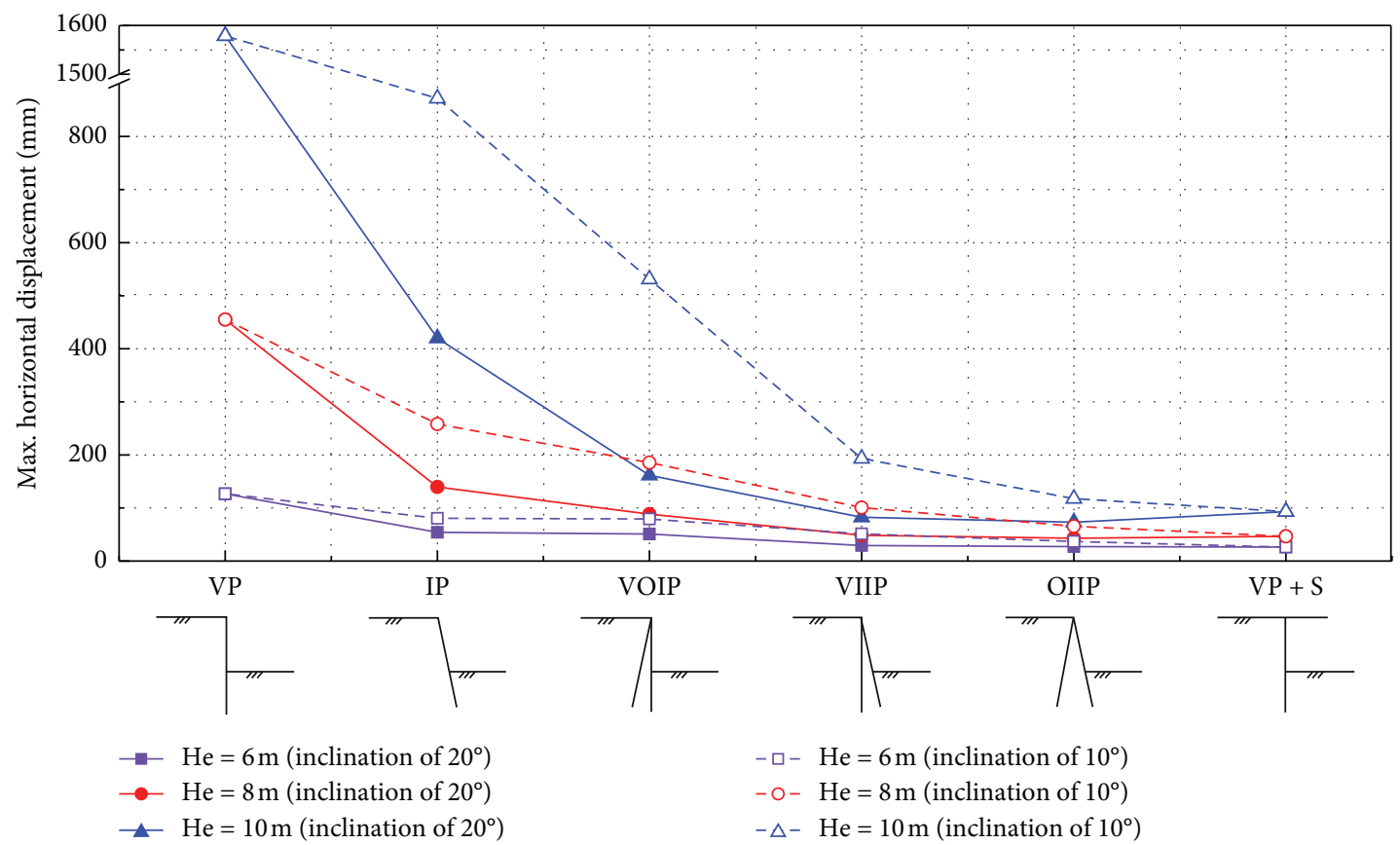

Figure 7: The maximum horizontal displacements of the retaining structures.

deformation as $\mathrm{VP}+\mathrm{S}$. Moreover, the omission of struts will simultaneously reduce costs and make the construction more convenient.

These new types of CIRSs can also reduce internal forces in the retaining piles, as shown in Figure 8. CIRSs, especially VIIP, have a smaller bending moment than VP and VP $+\mathrm{S}$, which can further decrease the cost of the retaining system.
In other words, CIRSs reduce the excavation-induced deformation but not at the cost of increasing the internal forces in the piles, indicating that CIRSs are a relatively rational structural configuration.

In this section, the performances of different types of inclined retaining structures were preliminarily introduced. Overall, for the excavations considered in this section, the 
retaining schemes of VIIP and OIIP are much better than the traditional retaining methods of $\mathrm{VP}$ and $\mathrm{VP}+\mathrm{S}$ and generate significant economical and social benefits. The working mechanisms responsible for the performance of each type of retaining structure are further investigated below.

\section{Working Mechanism of IP}

5.1. Displacement and Bending Moment. Excavations with a pile length of $15 \mathrm{~m}$ and a final depth of $6 \mathrm{~m}$ were studied to investigate the working mechanism of IP in this section. As shown in Figure 9, during excavation, the deflection mode of IP was the same as that of the VP, that is, the cantilever form (the largest displacement occurred at the pile top). However, for the same excavation depth, the displacement of IP was much smaller than that of VP. As the inclination angle of IP increased, the maximum horizontal displacement decreased significantly. For instance, compared with VP, the maximum displacements of IP with inclination angles of $10^{\circ}$ and $20^{\circ}$ were reduced by $36.62 \%$ and $57.32 \%$, respectively. The greater the inclination, the smaller the displacement. This pattern was similar to the conclusion based on sandy soil reported by Maeda et al. [6]. However, when the inclination became larger, the construction of the piles became more difficult, and the piles usually occupied more space. Therefore, the inclination angle should not be too large.

In addition, when the inclination angle of IP increased, the embedded length of the pile decreased due to the fixed pile length. For instance, the embedded depth of IP- $20^{\circ}$ was $6 \%$ less than that of VP. However, the lateral displacement of IP decreased rather than increased, which indicated that the inclination angle played an important role in controlling the pile displacement.

As shown in Figure 10, the bending moment distribution of IP was the same as that of VP. For the same excavation depth, the bending moment of IP was much smaller than that of VP. Additionally, with the increase in the inclination angle of IP, the location of the maximum bending moment became shallower, and the bending moment of the pile body decreased, which likely contributes to the decrease in the pile deflection. For an excavation depth of $6 \mathrm{~m}$, the maximum bending moments of IP with angles of $10^{\circ}$ and $20^{\circ}$ were $42.82 \%$ and $74.41 \%$ less, respectively, than that of VP.

5.2. Soil Stress Acting on Retaining Pile. As shown in Figure 11, for the same excavation depth, the normal stress acting on IP in the active zone was smaller than that on VP. Meanwhile, the greater the inclination angle, the smaller the normal stress acting on IP. This is the main reason that larger inclination angles are associated with smaller pile displacements and bending moments. In addition, because stress acting on the pile in the active and passive zones should be balanced, as the inclination angle increased, the normal stress acting on the IP in the passive zone exhibited a similar trend to that in the active zone.

For IP, because the piles were inclined, which was similar to a slope, vertical stresses in the soil elements close to the pile in the active zone were much smaller than those acting on VP. Correspondingly, the horizontal stresses in the soil elements were also smaller, as shown in Figure 12. This relationship may be the main reason that the normal stress acting on IP is smaller than that acting on VP.

\section{Working Mechanism of CIRSs}

6.1. The Deflection Patterns of CIRSs. For excavations with a pile length of $15 \mathrm{~m}$ and depth of $6 \mathrm{~m}$, as shown in Figure 13(a), when the inclination angle of the inward-inclined pile was $10^{\circ}$, the deflection mode of VIIP still presented as a cantilever type, similar to that of VP. However, at higher inclination angles, the deflection mode of the retaining piles gradually changed. For example, at $20^{\circ}$, the deflection mode exhibited bow shape, which is similar to that in the single prop retaining system $(\mathrm{VP}+\mathrm{S})$. The maximum lateral deformation occurred at $5.31 \mathrm{~m}$ below the pile top rather than at the pile top. In addition, the deflection of the inward-inclined pile was very close to that of the vertical pile in the integrated system of VIIP, which indicates that the entire retaining system deformed as a unit. Similar deflection phenomena were also observed in VOIP and OIIP and were not discussed herein for brevity.

6.2. The Deflection Reduction Mechanism of CIRSs. The above-mentioned analysis showed that, as the inclination angle of the inclined piles in CIRSs increased, the deflection decreased, and the deflection pattern changed. For the same inclination angle, the displacement of the pile body in OIIP was smallest, that in VIIP was intermediate, and that in VOIP was the largest among the studied CIRSs. In this section, the working mechanisms of CIRSs were explored and analyzed. Based on the numerical results, during the excavation, the entire retaining system of CIRSs deformed as a unit, and soil deformation was controlled through the interaction of the capping beam, vertical piles, inclined piles, and the soil between the piles. The working mechanism of the CIRSs was a combination of the inclined strut effect, rigid frame effect, earth berm effect, and gravity wall effect.

6.2.1. Inclined Strut Effect. As shown in Figure 13(b), as the inclination angle increased, the distribution of the bending moment of the vertical piles in VIIP gradually changed to resemble that of the vertical piles with a strut on top, which was similar to the change in the deflection mode discussed above. In other words, the load pattern of vertical piles in VIIP changed from the cantilever beam pattern to the hinged beam pattern due to the change in the pile head restraint condition. This change is one of the reasons why the bending moment and displacement decreased with increasing inclination angle.

The pile head restraint condition played an important role in the distributions of the displacement and the bending moment along the pile shaft. In the VIIP retaining system, the inclined pile experienced an axial compressive force, while the vertical pile experienced an axial tensile force, as shown in Figure 14. Therefore, the inclined pile acted as an inclined strut. Obviously, the shear force of the vertical pile 


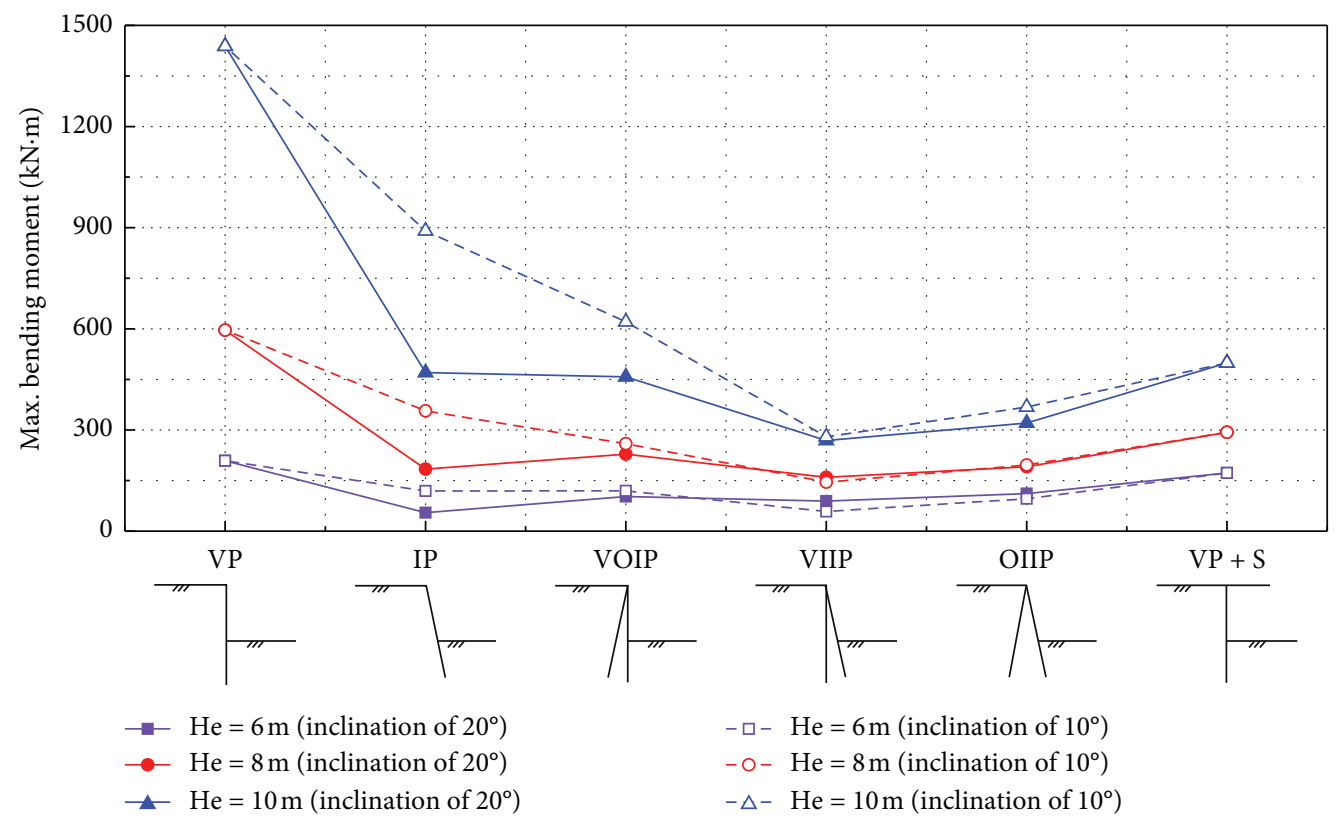

FIgURE 8: The maximum bending moments of the retaining piles.

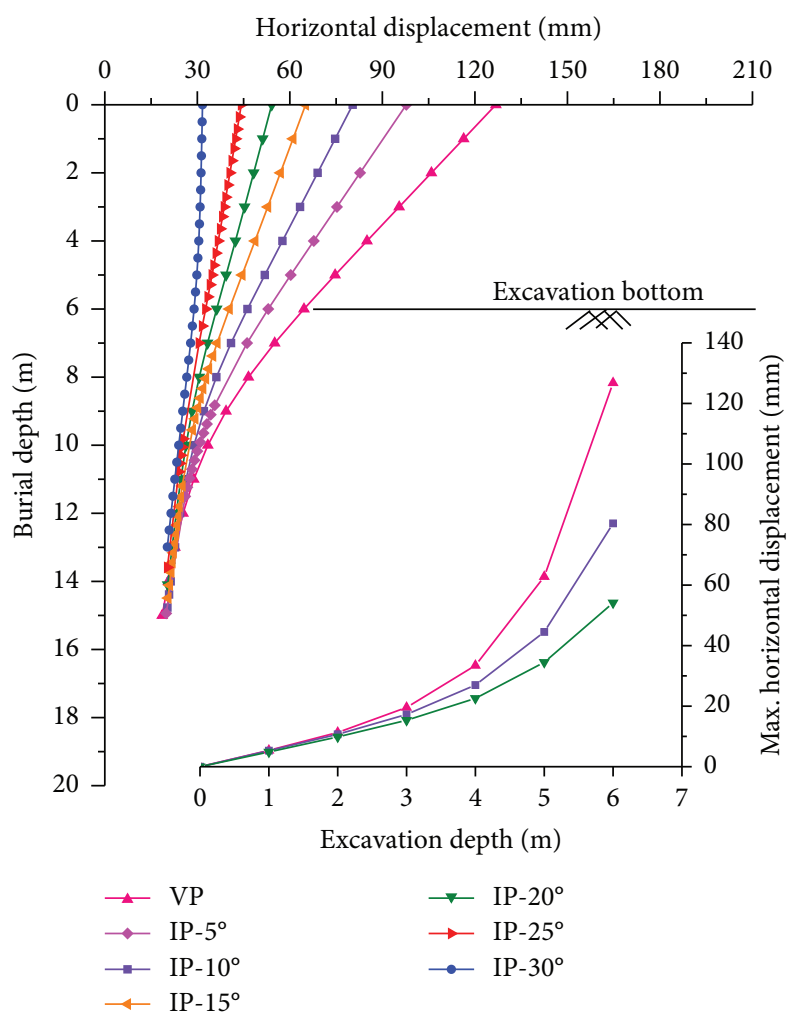

Figure 9: Horizontal displacements of VP and IP.

at the point below the capping beam was equal to the horizontal resultant supporting force provided by the inclined pile, which could be an index to quantitatively measure the strut effect. As shown in Figure 15, with increasing inclination angle, the horizontal supporting force of the vertical pile simultaneously increased, which means that the strut effect of the inclined pile increased. This behavior was a reason why the deformation and bending moment decreased as the inclination angle increased.

The inclined strut effect also existed in the VOIP and OIIP structures. As shown in Figure 14, in VOIP, the inclined pile and vertical pile were subjected to axial tensile 

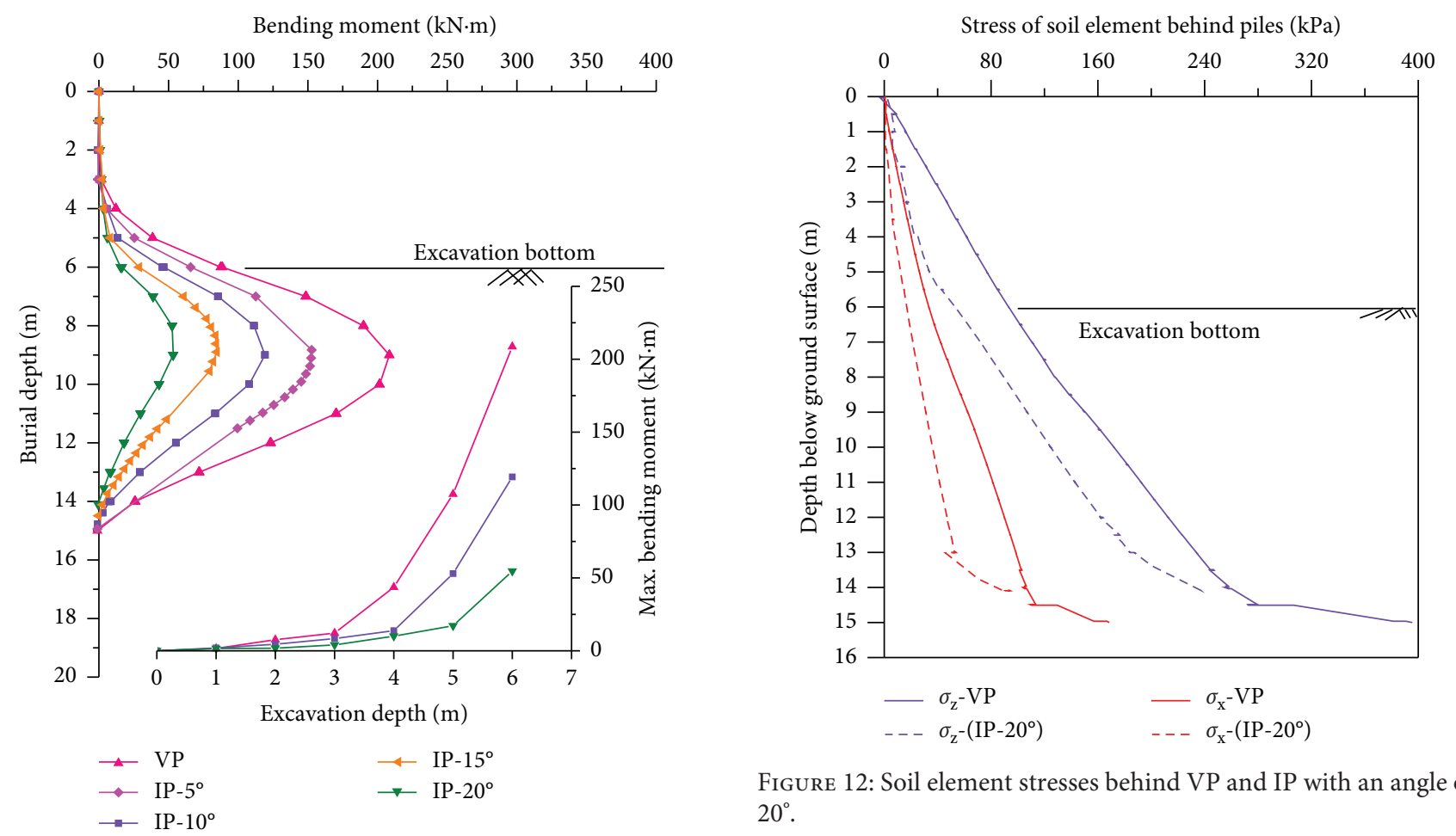

FIGURE 12: Soil element stresses behind VP and IP with an angle of $20^{\circ}$.

Figure 10: Bending moments of VP and IP.

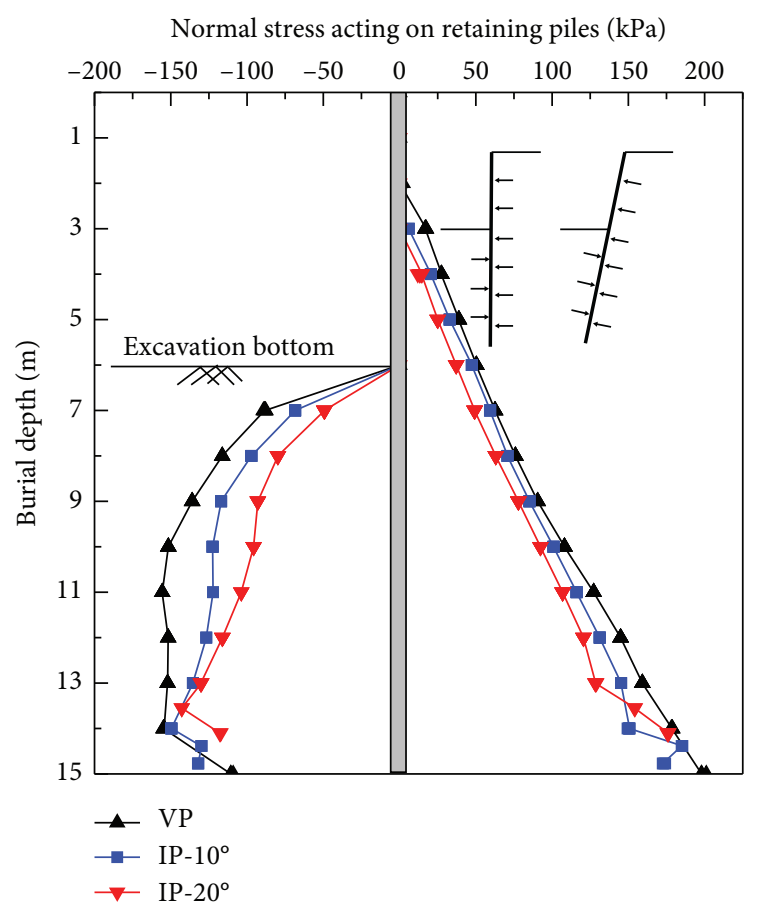

FIgURE 11: Normal stress acting on VP and IP at an excavation depth of $6 \mathrm{~m}$.

and compressive forces, respectively. The mechanical characteristics of outward-inclined piles were similar to those of anchors in the tieback retaining system. In OIIP, outward- and inward-inclined piles were subjected to axial tensile and compressive forces, respectively.

6.2.2. Rigid Frame Effect. The capping beam played a crucial role in CIRSs: it connected the piles with different inclination angles and made them work as a rigid frame. To investigate the influence of the capping beam, different connection conditions, that is, fixed, hinged, and free, were simulated for piles with different inclination angles. As shown in Figures 16(a)-16(c), when the vertical piles and inclined piles were not connected by the capping beam, they deformed independently and were both similar to that of cantilever piles. However, with the capping beam, regardless of whether the connection was fixed or hinged, the capping beam and retaining piles formed a spatial rigid frame, and the retaining piles cooperatively deformed. The pile displacements, especially the part above the excavation base, were significantly reduced compared with the case without a capping beam. Meanwhile, the deflection mode changed from the cantilever type to the bow shape, which was mainly because the strut force was transferred among the piles by capping beam. In other words, the rigid frame effect was the basis for realizing the inclined strut effect.

6.2.3. Earth Berm Effect. As shown in Figures 17(a) and 17(b), when the soil between the piles was removed, the displacements of the retaining piles significantly increased, and the resultant force of the earth pressures acting on the vertical piles provided by the soil in the passive zone decreased remarkably because of the removed soil. At the same time, the shear force at the top of the vertical piles increased, indicating that the strut force on the inclined piles increased. Figure 17(c) showed that, in the supporting structure of VIIP, the soil between the piles played a rather important role. This phenomenon could be explained as follows. 


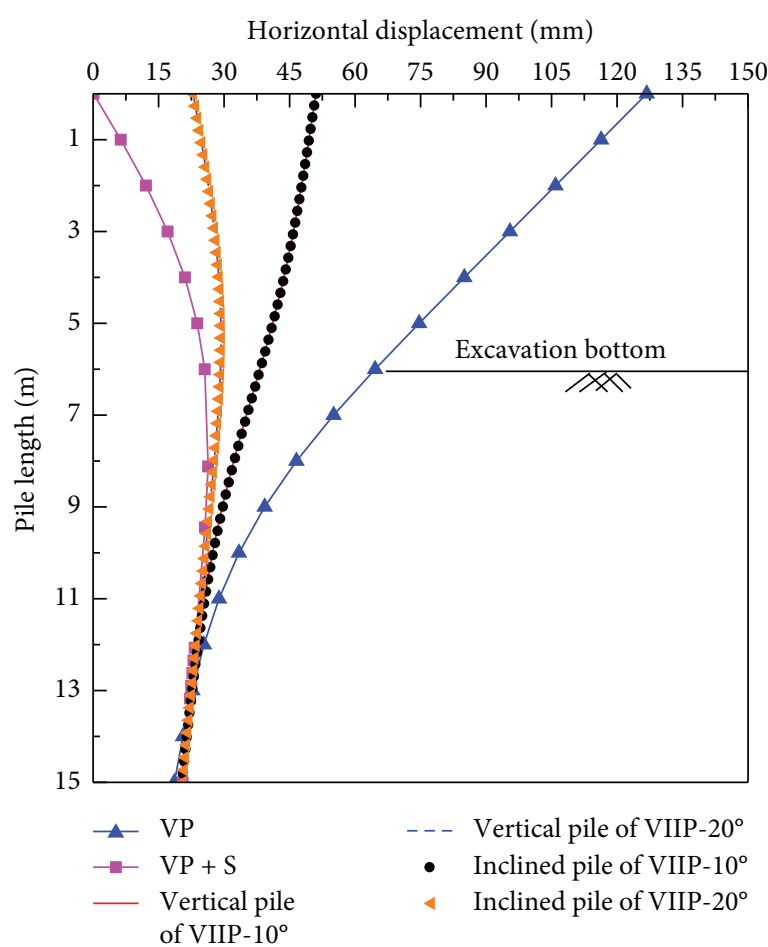

(a)

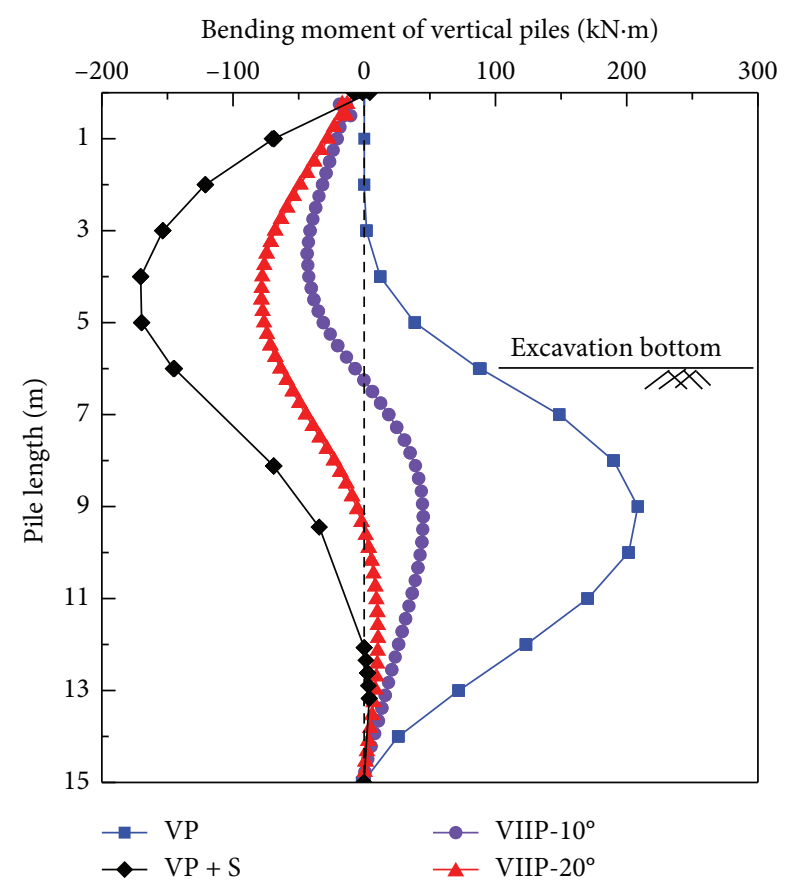

(b)

FIgURE 13: Comparison of horizontal displacements and bending moments of VP, VP + S, and VIIP. (a) Horizontal displacements. (b) Bending moments.

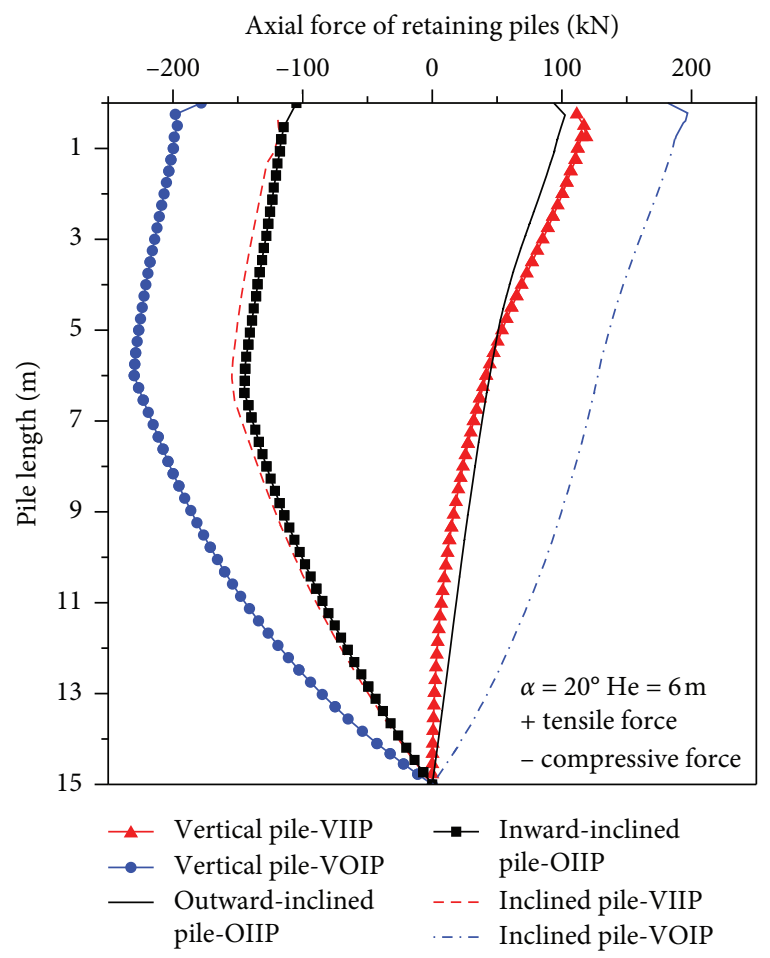

FIgURE 14: Axial forces of retaining piles in CIRSs.

In the horizontal direction, the earth pressures acting on the vertical piles in the active zone are balanced by the earth pressures in the passive zone and the horizontal strut forces

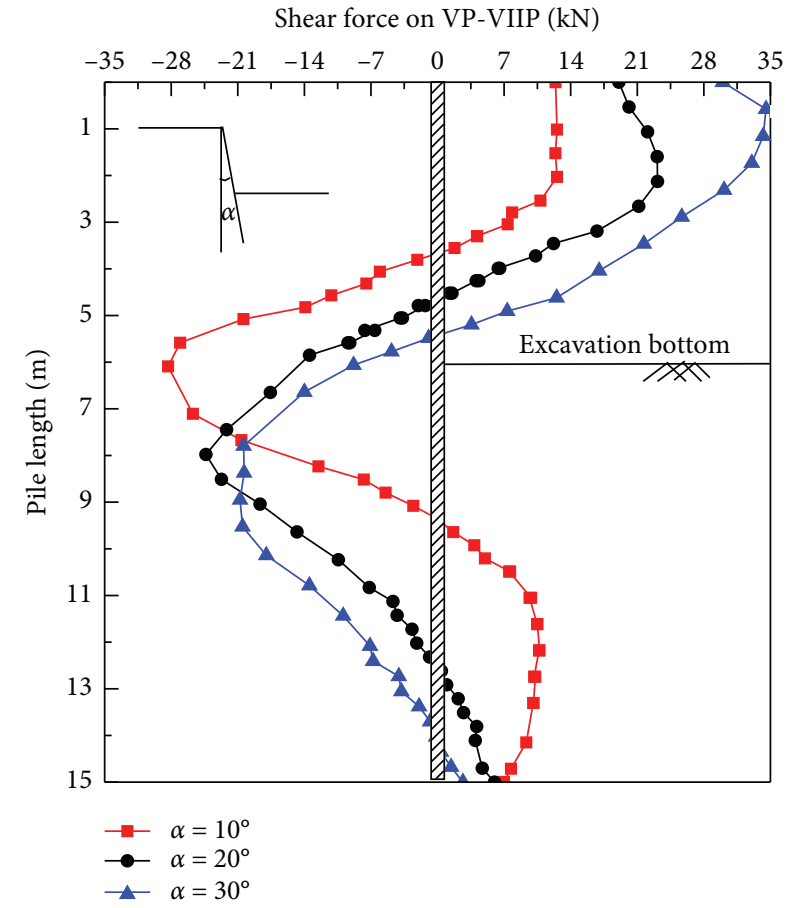

Figure 15: Shear forces acting on the VIIP-VP

of the inclined piles. When the soil between the piles was excavated, the earth pressure in the active area remained nearly unchanged. However, the total earth pressure on the passive side decreased. To maintain the balance in the 


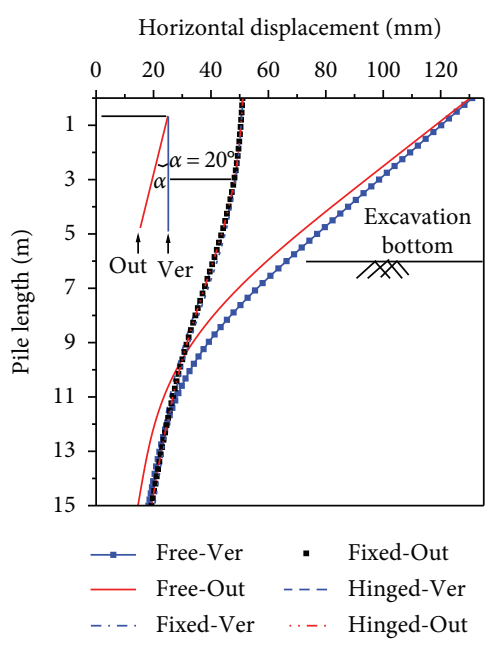

(a)

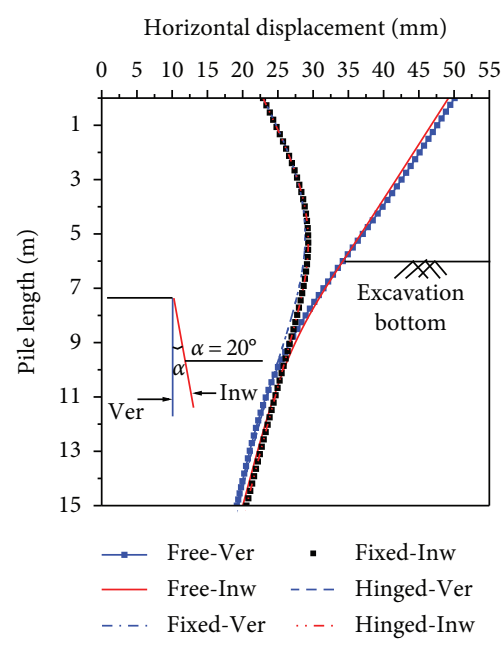

(b)

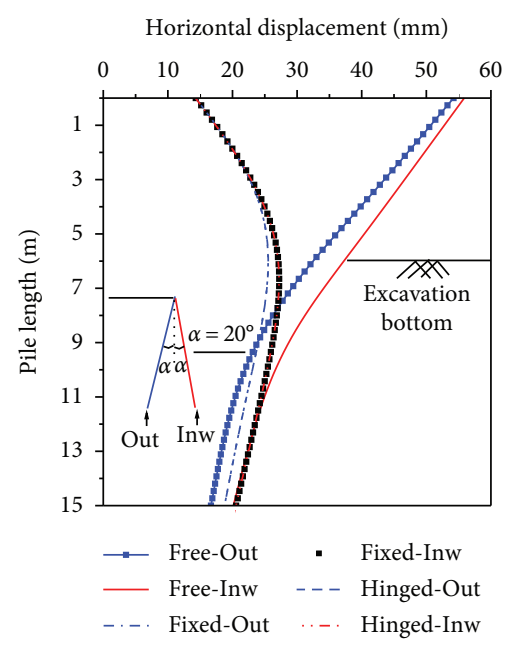

(c)

FIgURE 16: Comparison of horizontal displacements for different connection conditions at the pile top in CIRSs. (a) VOIP. (b) VIIP. (c) OIIP.

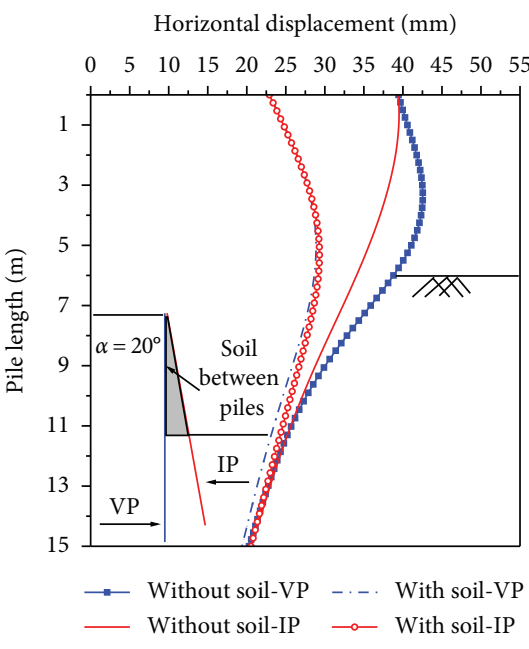

(a)

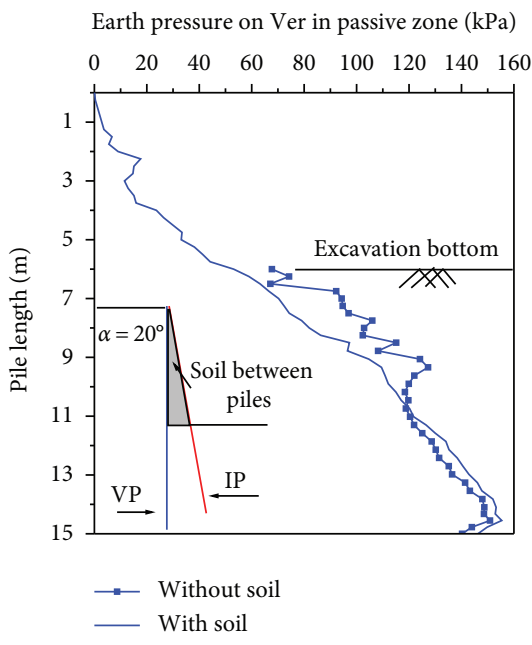

(b)

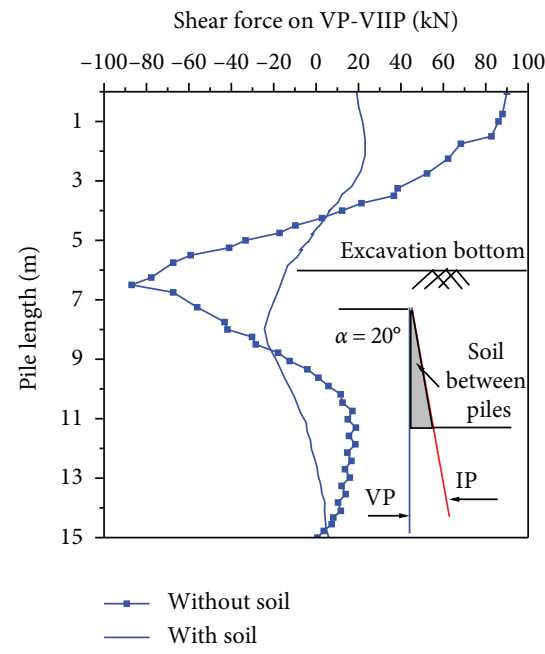

(c)

FIGURE 17: Comparison of VIIP with and without soil between retaining piles. (a) Horizontal displacements of VIIP. (b) Earth pressures acting on VIIP-VP in the passive zone. (c) Shear forces acting on VIIP-VP.

horizontal direction, the inclined strut force correspondingly increased, indicating that the axial forces of the inclined piles became larger and the relative displacement between the soil and the inclined piles also became larger. Overall, the soil in the triangular area between the vertical and inclined piles effectively improved the resistance of the soil in the passive zone and played a role similar to an earth berm [3, 12-14]. Therefore, the soil inside the VIIP should be carefully protected by the steel bar mesh and shot concrete to avoid failure. In OIIP, the earth berm effect also existed. However, there was no earth berm effect in VOIP. This difference was one of the reasons that OIIP and VIIP both had better performance than VOIP.

6.2.4. Gravity Wall Effect. As mentioned above, the deformations of the vertical and inclined piles were very close in CIRSs. Therefore, the retaining piles and the soil between the piles probably worked together to form a gravity retaining wall, which had a relatively large antioverturning+ ability. To investigate whether the CIRSs and the soil inside could be considered as an integrated mass, the retaining performances of the CIRSs were compared with that of a gravity wall with the same geometry. The model of the gravity wall was established by modeling the soil within each CIRS with a linear elastic model with an elastic modulus of $30 \mathrm{GPa}$, while the retaining piles were not activated. Then, the reinforced CIRS was turned into a concrete block.

The stability of the different types of CIRSs and the corresponding gravity walls were calculated using the strength reduction technique, and the safety factors were shown in Figure 18(a). For the same inclination angle, the stability safety factor of the OIIP-type gravity wall was larger than that of VIIP-type gravity wall, and the stability safety factor of the VOIP-type gravity wall was the smallest. The 


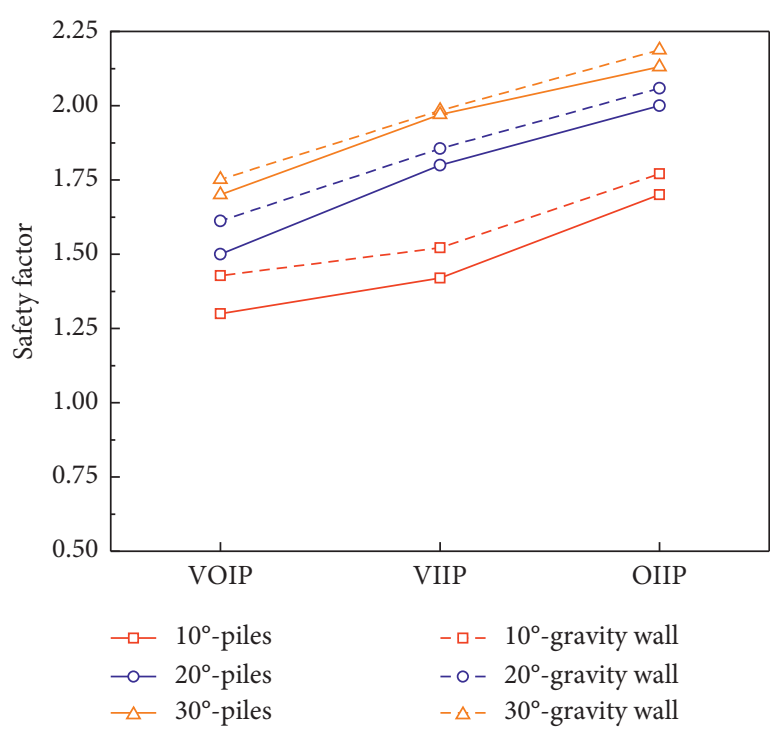

(a)

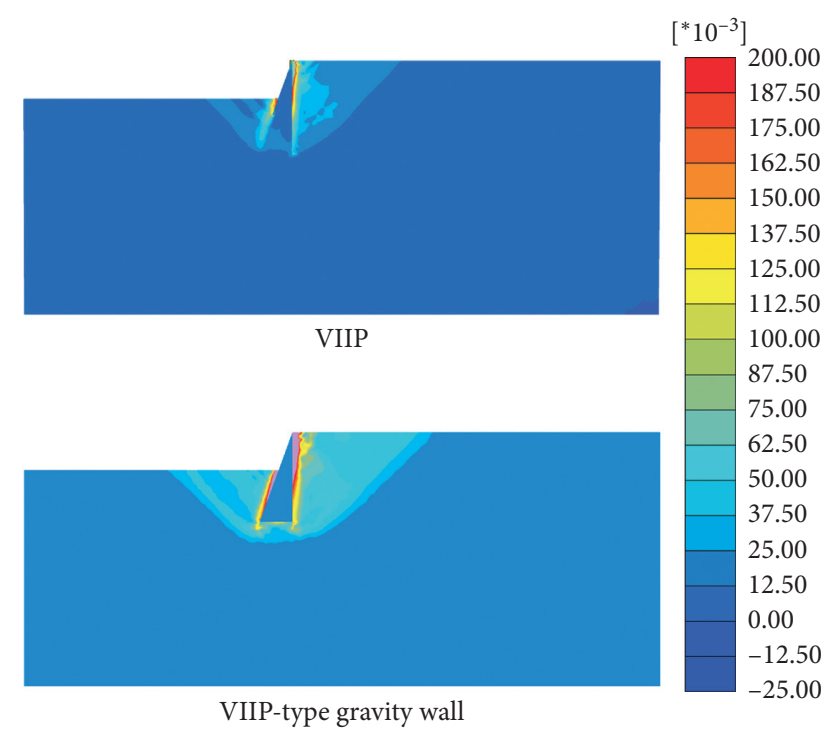

(b)

Figure 18: Comparison between CIRSs and corresponding gravity walls. (a) Safety factors. (b) Contours of shear strain increments.

safety factors of CIRSs were all close to those of corresponding gravity walls. Additionally, Figure 18(b) indicates that the failure mode of CIRSs and the corresponding gravity walls are also the same. Therefore, CIRS with a relatively large inclination angle indeed had a significant gravity wall effect, and the CIRS, which had a larger gravity wall effect, had better retaining performance.

\subsection{Parametric Study of the Influential Factors}

6.3.1. The Ratio of the Number of Inclined Piles to That of Vertical Piles in VIIP. In the previous sections, the number of vertical piles was equal to that of inclined piles in the VIIP retaining system. In this section, the influence of the ratio of the number of inclined piles to that of vertical piles $(N)$ on the performance of VIIP was examined using the case of VIIP with an inclination angle of $20^{\circ}$ and an excavation depth of $6 \mathrm{~m}$ as an example. As shown in Figure 19, as the ratio $N$ decreased, the maximum deformation of the retaining structure increased, and the deflection mode gradually changed to that of the cantilever pile, such as when $N$ was smaller than $1 / 8$. At the same time, the bending moments of both vertical and inclined piles first decreased and then increased significantly, as shown in Figure 20, and the mode of the bending moment also gradually changed to the cantilever pile mode when $N$ was smaller than $1 / 8$. The above phenomena could be explained as follows.

As shown in Figure 21, the maximum axial forces of inclined piles in VIIP first increased with decreasing ratio $N$. However, the axial forces did not increase when $N$ was smaller than $1 / 3$ because the friction force between the inclined piles and surrounding soil was fully mobilized, as shown in Figure 22. Here, the degree of mobilization of frictional resistance was expressed as the relative shear stress $\left(\tau_{\text {rel }}\right)$, which was defined as follows [15]:

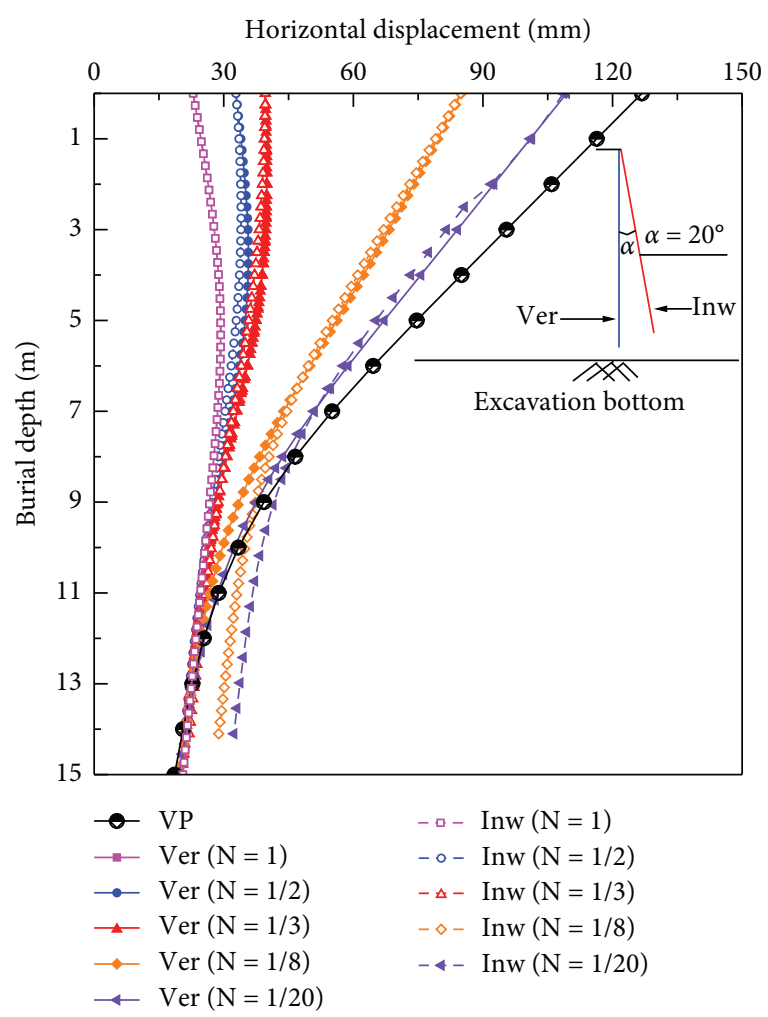

FIGURE 19: Comparison of horizontal displacements of VIIP with different $N$ values.

$$
\tau_{\text {rel }}=\frac{\tau_{\operatorname{mob}}}{\tau_{\max }}
$$

where $\left(\tau_{\max }\right)$ was the maximum shear stress of the soil and $\left(\tau_{\mathrm{mob}}\right)$ was the mobilized frictional resistance. A relative shear stress equaled to unity implies that the frictional resistance on the pile has been fully mobilized. 


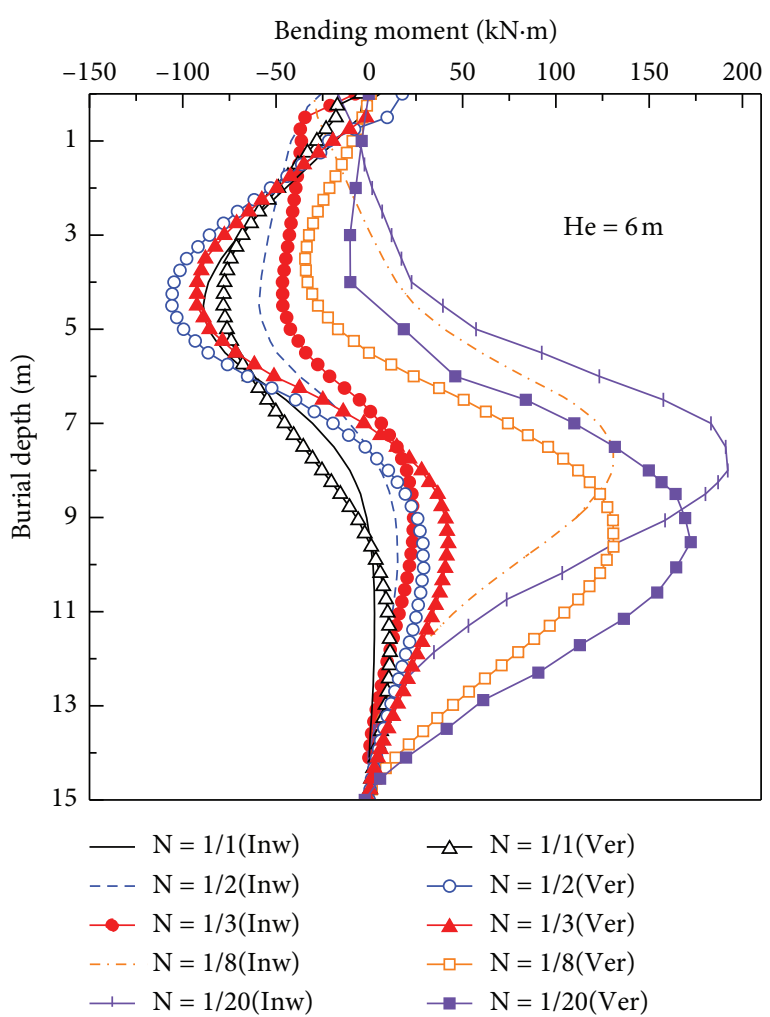

FIGURE 20: Comparison of bending moments of piles in VIIP with different $N$ values.

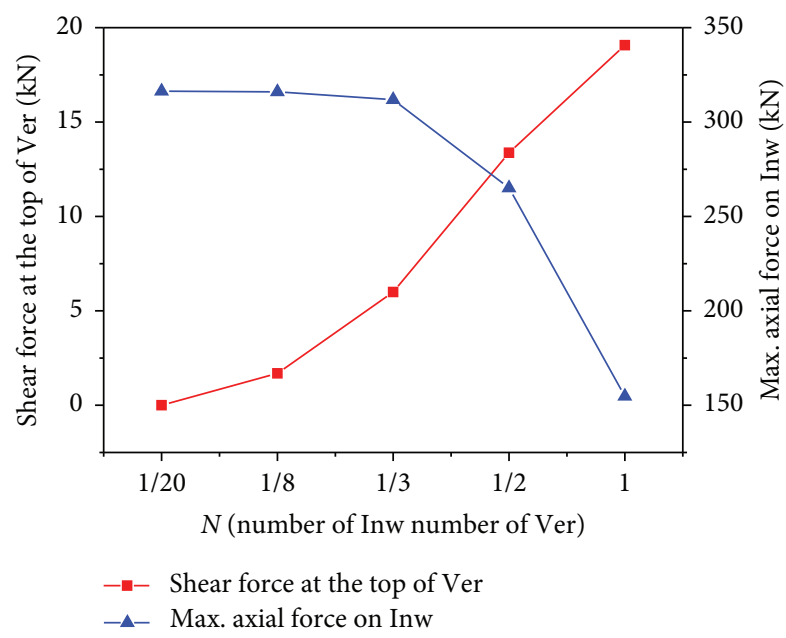

FIgURE 21: Comparison of the shear force at the top of vertical piles and the maximum axial force acting on inclined piles in VIIP with different $N$ values.

When the ratio $N$ decreased, although the maximum axial force of each inclined pile first increased and then gradually became stable, the average strut force of vertical piles (i.e., the average shear force at the top of the vertical pile) provided by the inclined piles gradually decreased, as shown in Figure 21, which means the strut effect provided by inclined piles became weaker. This should be the main reason that the deformation of the retaining system became

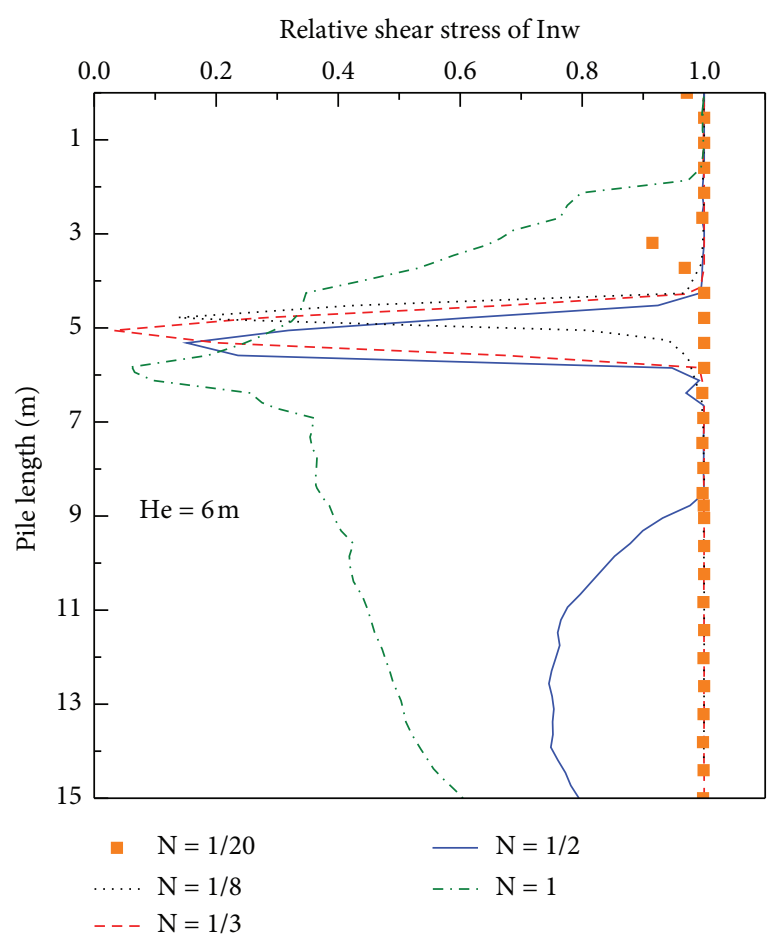

FIgURE 22: Comparison of the relative shear stresses of inwardinclined piles in VIIP with different $N$ values.

larger. Based on the above analysis, the ratio of the inclined pile in VIIP should be large enough to guarantee the performance of the VIIP.

6.3.2. The Length of Inward-Inclined Piles in VIIP. Based on the case with a pile length of $15 \mathrm{~m}$, an excavation depth of $6 \mathrm{~m}$, and an inclination angle of $20^{\circ}$, additional pile lengths of $11 \mathrm{~m}, 13 \mathrm{~m}, 17 \mathrm{~m}, 19 \mathrm{~m}, 21 \mathrm{~m}$, and $23 \mathrm{~m}$ were considered to investigate the effect of inward-inclined pile length on the performance of the retaining system. The maximum horizontal displacement, maximum axial force of the inclined pile, and shear force at the top of the vertical pile in VIIP with different inclined pile lengths were shown in Figure 23. With increasing inward-inclined pile length, the lateral deflection of VIIP decreased, but the rate of change decreased gradually. When the pile length increased to a certain value, the displacement of the retaining structure remained nearly constant.

The aforementioned phenomenon could be explained as follows. As shown in Figure 24, when the length of the inclined pile was $11 \mathrm{~m}$, the relative shear stress on the surface of the inward-inclined pile below the excavation bottom was rather large and even up to 1 at the pile end, which indicates that the lateral frictional resistance of the pile was fully mobilized. Therefore, to reduce the soil-pile relative displacement and the deformation of the retaining system, the length of the inward-inclined pile needed to be increased to provide larger frictional resistance.

When the pile length increased, the relative shear stress at the same depth (below the bottom of the excavation) decreased. Then, the relative displacement between the piles 


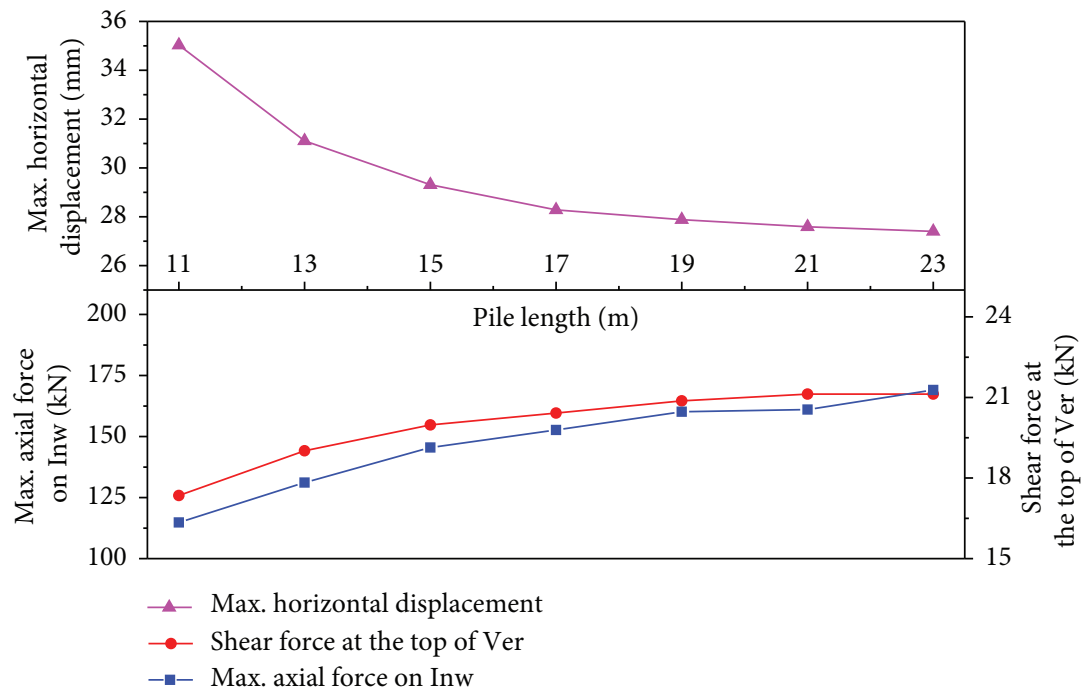

FIGURE 23: Comparison of maximum horizontal displacement, maximum axial force, and shear force of VIIP with different lengths of inward-inclined piles.

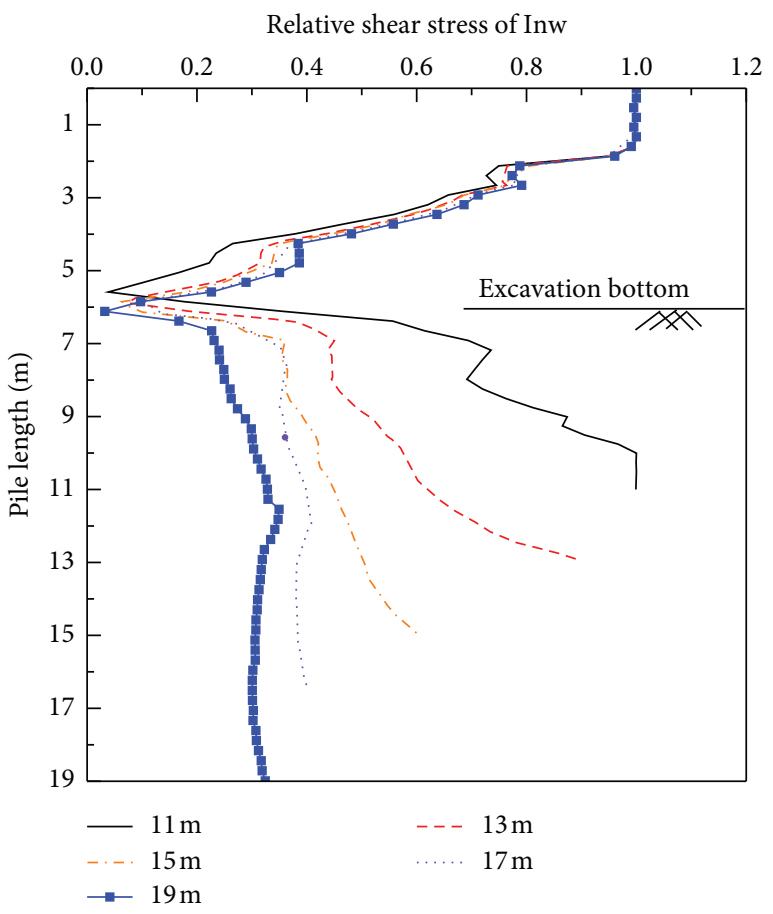

FIGURE 24: Comparison of the relative shear stress of inward-inclined piles with different lengths.

and the soil, that is, the pile displacement, and the degree of mobilization of the frictional force were reduced. As the pile length increased, the maximum axial force of the inclined pile (total friction resistance at the pile interface) and the shear force at the top of the vertical pile both increased, which indicates that the strut effect provided by the inclined pile increased. However, when the pile length increased to a certain value, such as $17 \mathrm{~m}$, these parameters ceased to increase substantially, as shown in Figure 24. In other words, the inclined strut effect did not increase obviously. Therefore, it was reasonable to select an appropriate length of inclined pile in practical engineering. For VIIP, the mobilized frictional force between the soil and inclined piles significantly influenced the performance of retaining structure.

\section{Conclusions}

In this study, the retaining performance and working mechanism of some new braceless retaining structures, such as IP and different types of CIRSs, were systematically investigated by $3 \mathrm{D}$ numerical simulations. The main conclusions are summarized as follows:

(1) Compared with VP, normal soil stress acting on inclined piles in the active zone decreased, and the displacement and bending moment of IP were significantly reduced.

(2) For different types of CIRSs, when the inclination angle increased, the maximum horizontal displacement decreased significantly, and the mode of deflection and bending moment of CIRSs gradually changed from the cantilever type to a bow shape, which was similar to that in the single prop retaining system $(\mathrm{VP}+\mathrm{S})$. When the inclined piles in different types of retaining systems had the same inclination angle, VOIP was better than IP, while OIIP and VIIP yielded the greatest performance. For relatively deeper excavations and smaller inclination angles, the performance of OIIP was slightly better than VIIP in reducing wall deflections.

(3) The main working mechanism of CIRS resulted from several combined effects, that is, the rigid frame effect, inclined strut effect, earth berm effect (not for VOIP), and gravity wall effect.

(i) The rigid frame effect and inclined strut effect: the capping beam in CIRSs connected the piles with different inclination angles and made them 
work as a rigid frame. The inward-inclined piles in VIIP functioned as inclined struts, while the outward-inclined piles in VOIP were similar to the anchors in the tieback retaining system. The rigid frame effect was the basis for realizing the inclined strut effect.

(ii) Earth berm effect: the soil in the triangular area between the vertical and inclined piles of VIIP effectively improved the resistance of the soil in the passive zone and played a role similar to an earth berm. In VOIP, the earth berm effect did not exist, which is one of the reasons that OIIP and VIIP both have better performance than VOIP.

(iii) Gravity wall effect: the system composed of retaining structure and soil between piles was similar to a gravity retaining wall, which had a relatively high overturning stability. For CIRSs, OIIP had the largest gravity wall effect, followed by VIIP and then VOIP. CIRSs, which had a large gravity wall effect, exhibited good retaining performance.

(iv) For VIIP, the degree of mobilization of the frictional force between the soil and the inclined piles significantly influenced the performance of the retaining structure. When the $N$ value (the ratio of the number of inclined piles to that of vertical piles) or the length of the inclined pile decreased, the mobilization degree of frictional resistance increased. However, both the maximum deformation and bending moment of the retaining structure increased because the strut effect provided by inclined piles became weaker. Therefore, the $N$ value and the length of inclined piles should be selected appropriately.

Practical projects and numerical results both showed that CIRSs, especially VIIP and OIIP, had much better retaining performance than those of vertical cantilever retaining structures and could even replace the retaining structure with a level of struts. The braceless retaining structure of CIRSs had several advantages, such as low cost, fast construction, and small deformation, and might be widely applied to excavations in soft soil areas.

\section{Abbreviations}

VP: The traditional cantilever structure consisting of vertical retaining piles

$\mathrm{VP}+\mathrm{S}$ : The vertical retaining pile structure with a level of struts

IP: $\quad$ Purely inclined piles structures

CIRSs: Composite inclined retaining structures

VIIP: Composite vertical and inward-inclined piles

$\mathrm{VII}_{\mathrm{n}} \mathrm{P}$ : Composite vertical and inward-inclined piles, $n$ represents the amount of inclined pile arranged continuously

VOIP: Composite vertical and outward-inclined retaining piles
OIIP: Composite outward- and inward-inclined retaining piles

Ver: Vertical pile in VIIP

Inw: Inclined pile in VIIP.

\section{Data Availability}

The data used to support the findings of this study are included within the article. The data used to support the findings of this study are available from the corresponding author upon request.

\section{Conflicts of Interest}

The authors declare that they have no conflicts of interest.

\section{Authors' Contributions}

Wenlong Cheng contributed to data curation; Peng Zhang contributed to methodology; Yuebin Zhao contributed to software; Gang Zheng contributed to supervision; Xinhao Li contributed to validation; Yuping Wang is responsible for writing of original draft; Xuesong Cheng is responsible for writing, review, and editing of the paper.

\section{Acknowledgments}

This work was supported by the National Key Research and Development Program of China (Grant no. 2017YFC0805407) and the National Natural Science Foundation of China (nos. 41630641 and 51708405). Their support is gratefully acknowledged.

\section{References}

[1] R. B. Peck, "Deep excavations and tunneling in soft ground," in Proceedings of the 7th International Conference on Soil Mechanics and Foundation Engineering, pp. 225-290, Mexico City, 1969.

[2] L. Mu and M. Huang, "Small strain based method for predicting three-dimensional soil displacements induced by braced excavation," Tunnelling and Underground Space Technology, vol. 52, pp. 12-22, 2016.

[3] H. J. Liao and C. C. Lin, "Case studies on bermed excavation in Taipei silty soil,” Canadian Geotechnical Journal, vol. 46, no. 8, pp. 889-902, 2009.

[4] C.-J. Lee, Y.-C. Wei, H.-T. Chen, Y.-Y. Chang, Y.-C. Lin, and W.-S. Huang, "Stability analysis of cantilever double soldierpiled walls in sandy soil," Journal of the Chinese Institute of Engineers, vol. 34, no. 4, pp. 449-465, 2011.

[5] G. Zheng, D. Nie, Y. Diao, J. Liu, and X. Cheng, "Numerical and experimental study of multi-bench retained excavations," Geomechanics and Engineering, vol. 13, no. 5, pp. 715-742, 2017.

[6] T. Maeda, Y. Shimada, S. Takahashi, and Y. Sakahira, "Design and construction of inclined-braceless excavation support applicable to deep excavation," in Proceedings of the 18th International Conference on Soil Mechanics and Geotechnical Engineering, Paris, France, September 2013.

[7] M. Seo, J.-C. Im, C. Kim, and J.-W. Yoo, "Study on the applicability of a retaining wall using batter piles in clay," 
Canadian Geotechnical Journal, vol. 53, no. 8, pp. 1195-1212, 2016.

[8] I. A. Jeldes, E. C. Drumm, R. M. Bennett, and N. Zisi, "Piling framed concrete retaining wall: design pressures and stability evaluation," Practice Periodical On Structural Design and Construction, vol. 20, no. 3, Article ID 040140413, 2015.

[9] P.-G. Hsieh, C.-Y. Ou, and W.-H. Hsieh, "Efficiency of excavations with buttress walls in reducing the deflection of the diaphragm wall," Acta Geotechnica, vol. 11, no. 5, pp. 10871102, 2016.

[10] G. Zheng, X. Yang, H. Zhou, Y. Du, J. Sun, and X. Yu, “A simplified prediction method for evaluating tunnel displacement induced by laterally adjacent excavations," Computers and Geotechnics, vol. 95, pp. 119-128, 2018.

[11] T. Schanz, P. A. Vermeer, and P. G. Bonnier, B. J Ronald and Brinkgreve, The hardening soil model: formulation and verification," in Beyond 2000 In Computational Geotechnics, pp. 281-296, CRC Press, Boca Raton, FL, USA, 1999.

[12] M. Georgiadis and C. Anagnostopoulos, "Effect of berms on sheet-pile wall behaviour," Géotechnique, vol. 48, no. 4, pp. 569-574, 1998.

[13] S. M. Gourvenec and W. Powrie, "Three-dimensional finite element analyses of embedded retaining walls supported by discontinuous earth berms," Canadian Geotechnical Journal, vol. 37, no. 5, pp. 1062-1077, 2000.

[14] M. El-Sherbiny, "Numerical analysis of embedded retaining walls supported by discontinuous unimproved and improved berms," M.Sc. Thesis, Cairo University, Giza, Egypt, 2016.

[15] P.-G. Hsieh and C.-Y. Ou, "Simplified approach to estimate the maximum wall deflection for deep excavations with cross walls in clay under the undrained condition," Acta Geotechnica, vol. 11, no. 1, pp. 177-189, 2016. 